\title{
Discharge Characteristics of Triangular-notch Thin-plate Weirs
}

GEOLOGICAL SURVEY WATER-SUPPLY PAPER 1617-B

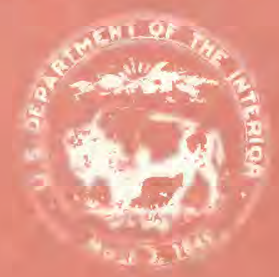





\section{Discharge Characteristics of Triangular-notch Thin-plate Weirs}

By JOHN SHEN

STUDIES OF FLOW OF WATER OVER WEIRS AND DAMS

GEOLOGICAL SURVEY WATER-SUPPLY PAPER 1617-B

A comprehensive study of the discharge characteristics of triangular-notch

thin-plate weirs

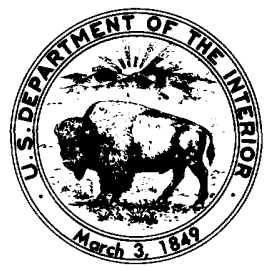




\section{UNITED STATES DEPARTMENT OF THE INTERIOR}

JAMES G. WATT, Secretary

GEOLOGICAL SURVEY

Doyle G. Frederick, Acting Director

\section{Library of Congress Cataloging in Publication Data}

Shen, John.

Discharge characteristics of triangular-notch thin-plate weirs.

Geological Survey water-supply paper ; 1617-B

Bibliography: $p$.

Supt. of Docs. no.: I 19.13:1617-B

1. Wiers. 2. Stream measurements. I. Title. II. Series: United States. Geological Survey. Water-supply paper ; $1617-\mathrm{B}$.

TC175.S5625 551.48'3'0287 80-607045

For sale by Superintendent of Documents, U.S. Government Printing Office Washington, D.C. 20402 


\section{PREFACE}

An initial draft of the report on the discharge characteristics of triangular-notch, thin-plate weirs was prepared in 1960. In draft form it was the basis for the development of recommended flow-measurement standards. In 1974, the discharge equation and the coefficients of discharge proposed in the report were adopted as part of an international standard. The equation and coefficients have been quoted extensively in several foreign national standards, books, and reports. In its present revised form, the report provides background and verification for the triangular-notch weir as a convenient, reliable, and inexpensive device for measuring small flows in open channels. 



\section{CONTENTS}

Preface _-_ III

Symbols ___

Abstract _- B1

Introduction _- 1

Description of the weir ___

Basic equation of discharge _ 3

Dimensional analysis _________- 4

Significance of the ratios in equation 3

Coefficient of discharge for one liquid _ 5

Modified equations for one liquid _._. 6

Review of the literature _-_____ 7

Thomson's experiments _____ 7

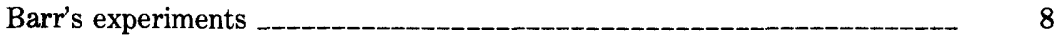

Barr-Strickland formula _______ 8

Cone's experiments _

Yarnall's experiments _-__- 10

Greve's experiments _-_______ 10

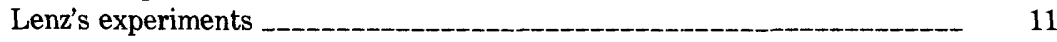

Experiments of Numachi, Kurokawa, and Hutizawa ___ 13

Other experiments ___ 13

Summary _-___ 15

Analysis of data __ 16

Evaluation of $k_{h}$

An alternative for $k_{h}$

Evaluation of $C_{e}$

Influence of $h / P$ and $P / B$

Comparison of formulas ___ 30

Basis of comparison _- 30

$90^{\circ}$-notch weir

Other notch angles _- 32

Conclusions _- 32

References _-___-__- 39

Supplemental information _________ 41

Requirements for precise measurements

Specifications for installation ___ 42

Restrictions on the geometric parameters

Restrictions on $h$ and $P$

Effect of neglecting $k_{h}$

Effect of approach-channel conditions ___ 43

Measurement of $\theta$

Measurement of $h$

Determination of gage zero 44 


\section{ILLUSTRATIONS}

FIGURE 1. The triangular-notch, thin-plate weir

2. Evaluation of $k_{h}$ illustrated with Numachi, Kurokawa, and Hutizawa data $\left(v=90^{\circ}\right)$

3. Evaluation of $k_{h}$ illustrated with Lenz data

11. Values of:

4. $k_{h}$ as a function of $\mathbf{v}$

5. $k$ as a function of $\mathbf{v}$

6. $C_{e}$, notch angles approximately $120^{\circ}$

7. $C_{e}$, notch angles approximately $90^{\circ}$

8. $C_{e}$, notch angles approximately $60^{\circ}$

9. $C_{e}$, notch angles approximately $45^{\circ}$

10. $C_{e}$, notch angles approximately $27^{\circ}$

11. $C_{e}$, notch angles of $10^{\circ}$ and $13^{\circ}$

12. Coefficient of discharge $C_{e}$ as a function of $\mathbf{v}$

13. Coefficient of discharge $C_{e}$ as a function of $h / P$ and $P / B\left(\mathrm{v}=90^{\circ}\right) \ldots \ldots$

14-19. Comparisons of formulas for:

14. $90^{\circ}$-notch weir

15. Notch angles of approximately $120^{\circ}$

16. Notch angles of approximately $60^{\circ}$

17. Notch angles of approximately $45^{\circ}$

18. Notch angles of approximately $27^{\circ}$

19. Notch angles of approximately $10^{\circ}$

20. Effect of using $h$ instead of $h_{e}$ in equation 6

\section{TABLES}

\section{CONVERSION FACTORS}

The inch-pound system of units is used throughout this report. The following factors may be used to convert inch-pound units to International System of Units (SI):

$\begin{array}{rcl}\text { Multiply inch-pound units } & \text { By } & \text { To obtain SI units } \\ & \text { Length } & \\ \mathrm{ft} \text { (feet) } & 0.30480 & \text { m (meters) } \\ \text { in (inch) } & 25.4 & \text { mm (millimeters) } \\ & \text { Area } & \\ \mathrm{ft}^{2} \text { (square feet) } & 0.09290 & \mathrm{~m}^{2} \text { (square meters) }\end{array}$


Multiply inch-pound units By

$\begin{array}{rlr} & \text { Volume } & \\ \mathrm{ft}^{3} \text { (cubic feet) } & 0.02832 & \mathrm{~m}^{3} \text { (cubic meters) } \\ & \text { Temperature } & \\ { }^{\circ} \mathrm{F} \text { (degrees Fahrenheit) } & 5 / 9\left({ }^{\circ} \mathrm{F}-32\right) & { }^{\circ} \mathrm{C} \text { (degrees Celsius) }\end{array}$

\title{
SYMBOLS
}

\author{
exponent in equation 16 \\ width of rectangular notch \\ width of approach channel \\ coefficient of discharge \\ coefficient of discharge (based on effective head) \\ relative error \\ acceleration due to gravity \\ piezometric head referred to vertex of notch \\ effective head \\ exponent in equation 9 \\ adjustment quantity \\ head-adjustment quantity \\ a length \\ coefficient in equation 12 \\ exponent in equation 12 \\ coefficient in equation 16 \\ exponent in equation 12 \\ height of weir notch above bottom of channel \\ discharge \\ Reynolds number \\ slope of sides of notch \\ Weber number \\ specific weight \\ included angle between sides of notch \\ dynamic viscosity \\ density \\ surface tension
}





\title{
DISCHARGE CHARAGTERISTICS OF TRIANGULAR-NOTGH THIN-PLATE WEIRS
}

\author{
By JoHN SHEN
}

\begin{abstract}
The triangular-notch, thin-plate weir is a convenient, inexpensive, and relatively precise flow-measuring instrument. It is frequently used to measure the flow of water in laboratories and in small, natural streams. This report includes an extensive review of the literature and presents a comprehensive analysis of the discharge characteristics of triangular-notch weirs. Previously published data are analyzed in the light of the effective-head concept, and a new discharge formula is proposed. Coefficients are recommended and requirements for precise measurements are described. Limits of applicability are discussed.
\end{abstract}

\section{INTRODUCTION}

The triangular-notch,thin-plate weir is used widely for measuring the flow of liquids in flumes and open channels. Simple in design and easily made from readily available materials, it is inexpensive, convenient to use, and easy to maintain. In permanent or portable form it is frequently used to measure the flow of water in laboratories and in small, natural streams. When several forms of weirs or flumes might be used, the triangular-notch weir is often preferred because of its greater accuracy at low flows or its lesser sensitivity to approach-channel geometry and velocity distribution. Within the range of conditions for which verification data are adequate, and with reasonable care in its construction, installation, and use, the triangular-notch, thin-plate weir is a relatively precise instrument.

The triangular-notch weir has been the subject of considerable experimental research and published discussion. Unfortunately, however, most of the laboratory investigations have been restricted to a narrow range of notch angles and channel geometries. The $90^{\circ}$-notch weir has been most extensively studied. With few exceptions, water has been the liquid used in laboratory tests.

A large number of empirical discharge formulas have been proposed for triangular-notch weirs. Most of these were designed to fit a par- 
ticular set of experimental data. None provides a comprehensive solution, even for a single liquid. Deficiencies in these formulas are concealed with numerous limits of applicability which greatly restrict their usefulness.

This report presents a comprehensive analysis of the discharge characteristics of triangular-notch, thin-plated weirs. Previously published data from various sources have been reanalyzed, and some of the traditional discharge formulas are compared with an original solution. The report is based on one of a series of studies of weirs and spillways which was undertaken by the U.S. Geological Survey under the direction of C. E. Kindsvater. Previously published reports in the series are concerned with broad-crested weirs (Tracy, 1957), rectangular, thin-plate weirs (Kindsvater and Carter, 1959), and embankment-shaped weirs (Kindsvater, 1964). Portions of this report are adapted from unpublished reports and drafts of weir standards prepared by C. E. Kindsvater.

\section{DESCRIPTION OF THE WEIR}

The weir which is the subject of this study is a symmetrical, V-shaped notch in a vertical thin plate. The line which bisects the angle of the notch is vertical and equidistant from the sides of the approach channel. The weir plate is smooth, plane, and perpendicular to the sides as well as the bottom of the approach channel. Figure 1 shows a triangular-notch, thin-plate weir installed at the end of a rectangular channel.

The crest surfaces of the weir notch are plane surfaces which form sharp, right-angle corners at their intersection with the upstream face of the weir plate. The width of the crest surface varies, but it is generally between $1 / 32$ and $1 / 16$ inch. If the weir plate is thicker than 1/16 inch, the downstream edges of the notch are chamfered to make an angle of not less than $45^{\circ}$ with the surface of the crest. Ideally, the channel upstream from the weir is straight, smooth, horizontal, rectangular, and of sufficient length to develop the normal (uniform flow) turbulence and velocity distribution for all discharges. Usually, however, it is less than ideal, and baffles or screens are provided in order to simulate a normal velocity distribution. Channel and tailwater conditions downstream from the weir are such as to permit a free, fully ventilated flow from the notch. Provisions for ventilation ensure that pressure on the nappe surfaces is atmospheric. The tailwater is low enough that it does not interfere with the ventilation of the nappe or free flow from the notch.

The head on the weir is the measured vertical distance from the water surface to the vertex of the notch. The head-measuring section is located a sufficient distance upstream from the weir to avoid the region of surface draw-down, and it is sufficiently close to the weir that the 


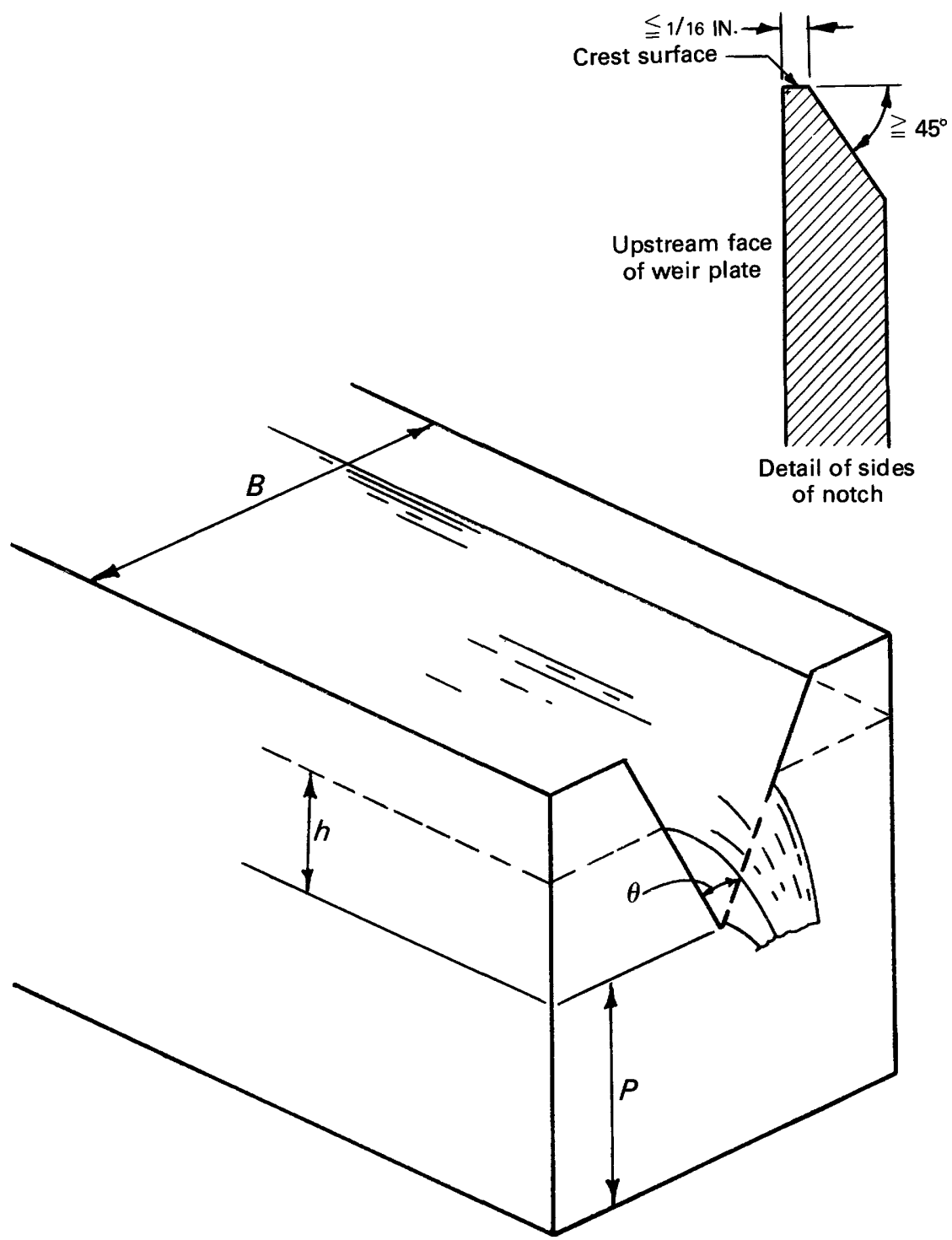

Figure 1. - The triangular-notch, thin-plate weir.

energy loss between the measuring section and the weir is negligible. A distance of 4 to $5 h_{\max }$ is recommended.

\section{BASIC EQUATION OF DISCHARGE}

The traditional equation of discharge for triangular-notch weirs is derived on the basis of an assumed analogy between the weir and the 
orifice. In the derivation, an approximate velocity equation is integrated over assumed area limits of the nappe in the plane of the weir. The result is an equation which is useful mainly because it is dimensionally correct and because it is used almost universally as the basis for the analysis of experimental data. It is used herein as the basic equation of discharge.

In its traditional form, the basic discharge equation is

$$
Q=C \frac{8}{15} \sqrt{2 g} \tan \frac{\theta}{2} h^{5 / 2},
$$

in which $Q$ is the volume rate of flow or discharge in cubic feet per second; $C$ is the nondimensional coefficient of discharge; $g$ is the acceleration due to gravity in feet per second per second; $\theta$ is the angle included between the sides of the notch, usually measured in degrees; and $h$ is the potentiometric head or height of the upstream liquid surface measured with respect to the vertex of the notch, in feet (in metric units, discharge would be stated in cubic meters per second, head in meters, and $g$ in meters per second per second; $C$, being nondimensional, would remain unchanged in numerical value).

Whereas $C$ is assumed to be a coefficient of contraction in the traditional derivation, in actuality it is an experimentally determined coefficient which is dependent upon all the variables needed to describe the channel, the weir, and the discharging liquid. Thus, in the absence of a rigorous theoretical solution, dimensional relations must be used to guide the analysis of experimental data on triangular-notch weirs.

\section{DIMENSIONAL ANALYSIS}

The principal variables needed to define the discharge characteristics of a triangular-notch, thin-plate weir in a rectangular channel (fig. 1) are: $Q$, the discharge; $B$, the width of the approach channel; $P$, the height of the notch vertex with respect to the floor of the approach channel; $h$, the head on the weir, referred to the vertex of the notch; $\theta$, the angle included between the sides of the notch; $\rho$, the density of the liquid; $\mu$, the viscosity of the liquid; $\sigma$, the surface tension of the liquid; and $\gamma$, the specific weight of the liquid. If the discharge is selected as the dependent variable, a complete statement of the discharge function is

$$
Q=f(B, P, h, \theta, \rho, \mu, \sigma, \gamma) .
$$

From this equation a nondimensional discharge ratio can be expressed as a function of five nondimensional ratios,

$$
\frac{Q}{h^{2} \sqrt{g h}}=f\left(\frac{h}{P}, \frac{h}{B}, \theta, \mathbf{R}, \mathbf{W}\right),
$$


in which $g=\gamma / \rho$. The dependent ratio in equation 3 is proportional to the coefficient of discharge. The first three ratios on the right-hand side describe the geometry of the weir, approach channel, and flow pattern; the last two ratios are the Reynolds number $(\mathbf{R})$ and the Weber number (W).

\section{SIGNIFICANCE OF THE RATIOS IN EQUATION 3}

The first independent ratio in equation $3, h / P$, is a measure of the depth-contraction characteristic. Because velocities in the channel upstream from the weir are proportional to the head, the $h / P$ ratio, in combination with $h / B$ and $\theta$, is also a measure of the relative magnitude of the velocity in the approach channel.

The $h / B$ ratio, in combination with $\theta$, is a measure of the widthcontraction characteristic (resembling $b / B$ for rectangular-notch weirs; see Kindsvater and Carter, 1959). A more convenient ratio to serve the same purpose is $P / B$, which is the quotient of $h / B$ divided by $h / P$. Thus, as a width-contraction ratio, $P / B$ depends on $h / P$ as well as $\theta$.

The notch angle, $\theta$, is a nondimensional measure of the shape of the weir notch. It is also a measure of the cross-sectional shape of the discharging liquid stream in the plane of the weir. In contrast with the discharge from most other forms of weirs, the shape of the stream from a triangular-notch weir is geometrically similar at all values of head, except as it is influenced by $h / P$ and $h / B$.

The Reynolds number, $\mathbf{R}$, is a measure of the relative influence of fluid viscosity. It is usually expressed as $\mathbf{R}=V L \rho / \mu$, in which $\mathrm{V}$ is a typical velocity, $L$ is a significant length, $\rho$ is the mass density, and $\mu$ is the dynamic viscosity of the liquid. In this instance the head, $h$, is the dominant length parameter. As the velocity is also a function of $h$, the influence represented by the Reynolds number can be expressed in terms of $h, \mu$, and $\rho$.

The Weber number, $\mathbf{W}$, is a measure of the relative influence of surface tension. It is usually expressed as $\mathbf{W}=\mathrm{V} \sqrt{L} / \sqrt{\sigma / \rho}$ in which $\sigma$ is the coefficient of surface tension of the liquid. As in the Reynolds number, $h$ is the most significant length parameter for use in the Weber number. Because $\mathrm{V}$ is also a function of $h$, the influence represented by the Weber number can be expressed in terms of $h, \sigma$, and $\rho$.

\section{COEFFIGIENT OF DISCHARGE FOR ONE LIQUID}

In equation 3 the dependent variable is proportional to the coefficient of discharge. The independent variables include three geometric ratios and two fluid-property ratios. As explained in the preceding section, one of the geometric ratios, $h / B$, can be replaced with $P / B$, which is more convenient because it is a constant for a given weir installation. 
For one liquid over a limited temperature range, $\mu, \sigma$, and $\rho$ can be assumed to be constants. Under these circumstances, the effects of viscosity and surface tension are related to the absolute magnitude of $h$ alone. Thus, both $\mathbf{R}$ and $\mathbf{W}$ in equation 3 can be replaced with the quantity $h$. It follows that, for one liquid and a limited range of temperatures,

$$
C=f\left(\frac{h}{P}, \frac{P}{B}, \theta, h\right) \text {. }
$$

In this report the only liquid of interest is water at normal atmospheric temperatures.

\section{MODIFIED EQUATIONS FOR ONE LIQUID}

The separate quantity $h$ in equation 4 represents the combined and inseparable effects of viscosity and surface tension on the coefficient of discharge. The principal effects of viscosity are those which are associated with flow pattern modifications due to boundary resistance and separation. The principal effects of surface tension are associated with the curvature of the nappe and "clinging" on the crest surfaces of the notch. A detailed discussion of these effects is contained in the paper by Kindsvater and Carter (1959) on rectangular, thin-plate weirs. The following pertinent conclusions are drawn from that paper:

1. The combined effects of viscosity and surface tension on a notch weir are commensurate with fictitious increases in head and notch width.

2. The coefficient of discharge can be expressed in terms of the geometric ratios alone if the effects of viscosity and surface tension are accounted for by an adjustment of the measured values of head and notch width (for triangular-notch weirs, for which notch width is a function of $h$, only the measured values of head need be adjusted.)

3 . The adjustment of measured values of $h$ can be accomplished very simply, as indicated by the equation

$$
h_{e}=h+k_{h},
$$

in which $h_{e}$ is the effective (adjusted) head, $h$ is the measured head, and $k_{h}$ is a quantity which must be determined by experiment. ${ }^{1}$

4. Use of the effective head, $h_{e}$, in place of $h$, results in the following modifications of equations 1 and 4 for one liquid:

\footnotetext{
${ }^{1}$ Subsequent to the initial exposition of the "effective-head concept" by Kindsvater in 1956, it was applied successfully to several kinds of weirs by others (Carter, 1956; Schlag, 1962a; Schlag, 1962b; John Shen, written commun., 1962; Burgess and White, 1966, among others).
} 


$$
Q=C_{e} \frac{8}{15} \sqrt{2 g} \tan \frac{\theta}{2} h_{e}^{6 / 2}
$$

and

$$
C_{e}=f\left(\frac{h}{P}, \frac{P}{B}, \theta\right)
$$

Equation 6, in combination with experimentally derived values of $C_{e}$ and $k_{h}$, is proposed as a new, comprehensive discharge formula for triangular-notch, thin-plate weirs. ${ }^{2}$ Equation 7 defines $C_{e}$ as a function of geometry alone; i.e., independent of fluid-property effects represented by $h$. The adequacy and validity of these equations must be examined in the light of experimental data. The data used for this purpose have been abstracted from the literature.

\section{REVIEW OF THE LITERATURE}

\section{THOMSON'S EXPERIMENTS}

James Thomson, Professor of Civil Engineering at Queen's College, Belfast, Ireland, was among the earliest experimental investigators of the triangular-notch weir (Thomson, 1858, 1861). Thomson's experiments were made at a pond in an open field near Belfast. His purpose in making the tests was to acquire experimental evidence to support his proposal that triangular-notch weirs be used instead of rectangular weirs when the range of discharges to be measured included very small flows.

Professor Thomson's experimental equipment was crude by modern standards, and the range of conditions covered by his experiments was small. Nevertheless, some of his conclusions are pertinent here. Two notch angles, $90^{\circ}$ and $127^{\circ}$, were investigated. For the $90^{\circ}$ notch, Thomson recommended a constant value of $C$ (eq 1$)=0.593$. For the $127^{\circ}$ notch, he recommended $C=0.617$. Experiments made with the vertex of the notch at the level of the channel $(P=0)$, with the channel wide enough to provide negligible approach velocities, showed no appreciable influence which could be attributed directly to the value of $P$. With reference to the $127^{\circ}$ notch, Thomson noted an instability which he associated with the nappe's tendency to cling to the upper portions of the wetted crest surfaces. This led him to recommend for larger discharges that two or more $90^{\circ}$ notches (located side-by-side) be used instead of a single, large-angle notch.

\footnotetext{
${ }^{2}$ Equation 6 is described as the Kindsvater-Shen equation in the international standard (International Standards Organization, 1975) which was based in part on the 1960 draft of this report.
} 


\section{BARR'S EXPERIMENTS}

One of the most extensive among the early investigations began as an effort to check Thomson's conclusions (Barr, 1910). James Barr, then a Carnegie Research Scholar at Glasgow University, Scotland, performed his experiments in the James Watt Engineering Laboratories. Many of the traditional formulas for $90^{\circ}$-notch weirs are based on the results of Barr's experiments. Because his instrumentation and technique were good, his data are among those selected for analysis in this report.

Barr's experiments were performed primarily with three different $90^{\circ}$ notches. One weir was made of brass and two of iron plate. The upstream edges of the crest surfaces were square and sharp, and the width of the crest surfaces varied from $1 / 16$ inch to $1 / 12$ inch. A $54^{\circ}$ notch was also tested. The weirs were placed at the end of a channel which was 4 feet wide and 22 feet long. The vertex of the notches was about 2 feet above the floor of the approach channel for most of Barr's tests.

To investigate the effect of channel width and weir height, Barr used false walls and floors in the approach channel. The false walls extended 3 feet upstream, and the floor extended 3.5 feet upstream from the weir plate. Tests were also made to investigate the effects of roughness and projections on the upstream face of the weir. For this purpose, roughness was produced with a mixture of varnish and emery particles. Projections consisted of narrow metal strips which were bolted to the weir bulkhead.

On the basis of his experiments, Barr disagreed with Thomson's conclusion that the coefficient of discharge was a constant. His results indicated that the coefficient varied with the head. He concluded that the coefficient was increased by roughness and projections on the upstream face of the weir. He also concluded that the coefficient was independent of channel width if the width was at least eight times the head. For channel widths less than $8 h$, the coefficient increased as the width decreased. He also found that the coefficient decreased slightly with decreasing values of $P$ when $P$ was less than $K_{h}$, where $K$ is a coefficient equal in value to the head in inches.

\section{BARR-STRICKLAND FORMULA}

A widely quoted formula for $90^{\circ}$-notch weirs was derived by T. P. Strickland (1910) on the basis of Barr's experiments. As an equation for $C$, the Barr-Strickland formula is

$$
C=0.566+\frac{0.0157}{\sqrt{h}} .
$$




\section{CONE'S EXPERIMENTS}

Subsequent to the work of Thomson and Barr, the triangular-notch weir was widely used and extensively investigated in the United States as well as Europe. One of the earliest investigators in this country was V. M. Cone (1916), whose work on rectangular, trapezoidal, circular, and triangular thin-plate weirs was performed in the laboratory of the Colorado Agricultural Experiment Station at Fort Collins, Colorado, under the sponsorship of the U.S. Department of Agriculture.

The channel used for Cone's experiments was 20 feet long, 10 feet wide, and 6 feet deep. The vertex of the weir notch was 4.5 feet above the channel floor. Cone tested five triangular-notch weirs, with notch angles equal to $120^{\circ}, 90^{\circ}, 60^{\circ}, 30^{\circ}$, and $28^{\circ} 4^{\prime}$. All weirs were made of $1 / 4$-inch brass plate, with sharp upstream edges and crest-surface widths of $1 / 16$ inch (except the $120^{\circ}$ notch, for which the crest surface was $1 / 32$-inch wide). A total of 98 tests was made, covering a range of heads from 0.20 to 1.35 feet.

Cone, like Thomson, observed that notch angles of $120^{\circ}$ or larger were impractical because of the tendency for the nappe to cling to the upper portion of the wetted crest surfaces. On the basis of his experiments, he proposed a general formula for all notch angles between $28^{\circ}$ and $109^{\circ}$. As an equation for $C$, Cone's formula is

$$
C=\frac{0.576}{h^{j}}+\frac{0.00584}{S h^{j}},
$$

in which $S$ is the slope of the sides of the notch, expressed decimally, and

$$
j=\frac{0.0195}{S^{0.75}} .
$$

Cone also made a limited number of tests on the $90^{\circ}$ notch with the floor of the approach channel at the vertex of the notch. He concluded that the coefficient of discharge was slightly greater for $P=0$ than for $P=4.5$ feet. Thus, the results of tests made by Thomson, Barr, and Cone give conflicting indications of the influence of $P$.

With regard to crest-surface width, Cone concluded that "thin edge" and "sharp edge" need not imply that the weir notches are knife-edged. $\mathrm{He}$ observed that the allowable width depends on the head. Experiments indicated that "edges $1 / 4$-inch thick showed that while water would adhere to the notch edges with a head of 0.15 foot, there was no adherence with heads of 0.2 foot and over." He recommended that head measurements "be made either at a distance of at least $4 h$ upstream from the notch or at a distance of at least $2 h$ sidewise from the end of the crest of the notch" (Cone, 1916, p. 1089-1090). 


\section{YARNALL'S EXPERIMENTS}

D. R. Yarnall's principal work on triangular-notch weirs was based on research performed at the University of Pennsylvania (Yarnall, $1912,1926)$. His tests were made in a channel 6 feet wide and 9 feet long, with only 4 feet 8 inches between baffles and weir plate. The vertical distance from the vertex of the notch to the floor of the approach channel was 3.6 feet. The notch angles tested by Yarnall were $90^{\circ}$, $53^{\circ} 8^{\prime}, 27^{\circ}$, and $13^{\circ} 8^{\prime}$, and the width of the weir-crest surfaces was $1 / 32$ inch. A total of 61 tests were made on the four weirs, with a range of heads from 0.35 to 1.26 feet.

A notable feature of Yarnall's experiments was the short channel, which he had equipped with simple but effective baffles in order to produce a uniform velocity distribution upstream from the weir. Such demonstrations of the practicality of short weir "boxes" led to their widespread use as portable flow-meters in hydraulics laboratories, industrial plants, and field applications.

\section{GREVE'S EXPERIMENTS}

The most extensive investigation of different notch angles is represented by the work of Professor F. W. Greve at Purdue University (Greve, 1932). A total of 16 different weirs, with notch angles varying from $25^{\circ} 03^{\prime}$ to $118^{\circ} 11^{\prime}$, were investigated. All of the weirs were tested in a channel which was 5 feet wide and 16 feet long from baffles to weir plate. The distance from notch vertex to channel floor varied from 4.5 to 5 feet. The weir plates were cut from $3 / 8$-inch soft steel plates, with the downstream edges of the notches beveled to form a crest which was sharp on the upstream edge and 1/32-inch wide. The report stated that the plates were coated with asphalt paint, but not specifically that the paint was applied to the surfaces in the immediate vicinity of the crest. Thus, there is some uncertainty regarding the smoothness of the upstream face and the sharpness and width of the crest during the tests. Table 1 shows a summary of the scope of Greve's experiments.

In summarizing the results of his tests, Greve presented a comprehensive discharge formula for all notch angles between $20^{\circ}$ and $120^{\circ}$. His formula for $C$ is

$$
C=\frac{0.585}{\left(\tan \frac{\theta}{2}\right)^{0.004} h^{0.03}} .
$$

Referring to supplementary tests on a $10^{\circ}$ notch, Greve observed that the small notch exhibited characteristics of "excessive clinging" and gave "results which were not in harmony" with his general formula. 
TABLE 1.-Scope of Greve's experiments

\begin{tabular}{|c|c|c|c|c|c|c|}
\hline \multirow{2}{*}{ Series } & \multirow{2}{*}{ Notch angle } & \multirow{2}{*}{$\begin{array}{c}\text { Number } \\
\text { of } \\
\text { tests }\end{array}$} & \multicolumn{2}{|c|}{ Range of head (ft) } & \multicolumn{2}{|c|}{$\begin{array}{l}\text { Range of temperature } \\
\left({ }^{\circ} \mathrm{F}\right)\end{array}$} \\
\hline & & & From & To & From & To \\
\hline W-3.3 & $25^{\circ} 03^{\prime}$ & 37 & 0.167 & 0.991 & 62 & 69 \\
\hline W-3.4 & $36^{\circ} 53^{\prime}$ & 30 & .146 & 1.090 & 63 & 71 \\
\hline$W-3.0 \ldots$ & $40^{\circ} 00^{\prime}$ & 27 & .282 & .854 & 69 & 73 \\
\hline W-3.1 & $44^{\circ} 24^{\prime}$ & 46 & .201 & 1.025 & 69 & 79 \\
\hline W-3.5 & $45^{\circ} 23^{\prime}$ & 27 & .153 & 1.178 & 65 & 67 \\
\hline W-3.6 _ & $45^{\circ} 23^{\prime}$ & 13 & .251 & 1.128 & 71 & 73 \\
\hline $\mathrm{W}-3.6 \mathrm{~A}$ & $53^{\circ} 55^{\prime}$ & 32 & .241 & 1.211 & 72 & 73 \\
\hline W-3.7 & $53^{\circ} 55^{\prime}$ & 17 & .190 & 1.199 & 71 & 72 \\
\hline W-3.8 & $59^{\circ} 07^{\prime}$ & 31 & .217 & 1.254 & 77 & 84 \\
\hline W-3.9 _ & $69^{\circ} 38^{\prime}$ & 43 & .243 & 1.216 & 71 & 75 \\
\hline W-3.10 _ & $81^{\circ} 52^{\prime}$ & 33 & .342 & 1.199 & 74 & 77 \\
\hline W-3.11 & $94^{\circ} 39^{\prime}$ & 46 & .219 & 1.111 & 74 & 77 \\
\hline W-3.12 & $98^{\circ} 47.5^{\prime}$ & 22 & .318 & .988 & 69 & 74 \\
\hline W-3.13 & $102^{\circ} 20^{\prime}$ & 31 & .257 & 1.047 & 72 & 76 \\
\hline W-3.14 & $110^{\circ} 00^{\prime}$ & 36 & .217 & .945 & 74 & 81 \\
\hline W-3.15 _ & $118^{\circ} 11^{\prime}$ & 30 & .251 & .725 & 80 & 82 \\
\hline
\end{tabular}

A final statement, based on attempts to correlate his results with the results of others, is noteworthy: "it is unwise to formulate a general expression for discharge from data compiled from different sources unless such expression incorporates certain factors which correlate variation in the physical characteristics of the testing plants" (Greve, 1932, p. 33).

\section{LENZ'S EXPERIMENTS}

The effect of viscosity and surface tension were objectives of the experiments made by Professor Arno T. Lenz at the University of Wisconsin (Lenz, 1943). Using water and two different oils at temperatures ranging from $51^{\circ}$ to $102^{\circ} \mathrm{F}$, Lenz's tests covered a range of viscosities from 1 to 150 times that of water, surface tensions from 1 to 0.41 times that of water, and densities from 1 to 0.85 times that of water. Six different weirs, with notch angles ranging from $10^{\circ}$ to $90^{\circ}$, were investigated. The tests were made in a steel tank 3.5 feet wide and 7 feet 9 inches long from baffles to weir plate. The vertex of the notch was 3 feet above the floor of the tank. The weir plates were made of $1 / 8$-inch brass, sharp-edged on the upstream side and beveled on the downstream side to form a sharp-edged crest $1 / 32$-inch wide. Table 2 shows a summary of the scope of Lenz's tests which, for the purpose of this report, includes only those experiments using water. 
TABLE 2.-Scope of Lenz's experiments with water

\begin{tabular}{|c|c|c|c|c|c|c|}
\hline \multirow{2}{*}{ Series } & \multirow{2}{*}{ Notch angle } & \multirow{2}{*}{$\begin{array}{c}\text { Number } \\
\text { of } \\
\text { tests }\end{array}$} & \multicolumn{2}{|c|}{ Range of head (ft) } & \multicolumn{2}{|c|}{$\begin{array}{l}\text { Range of temperatures } \\
\left({ }^{\circ} \mathrm{F}\right)\end{array}$} \\
\hline & & & From & To & From & To \\
\hline $90 \mathrm{D}$ & $89^{\circ} 53.2^{\prime}$ & 14 & 0.23 & 0.50 & 61 & 63 \\
\hline $60 \mathrm{D}$ & $59^{\circ} 51.0^{\prime}$ & 33 & .16 & .60 & 54 & 62 \\
\hline $45 D_{-}$ & $44^{\circ} 40.0^{\prime}$ & 18 & .20 & .55 & 56 & 60 \\
\hline $28 \mathrm{D}_{\ldots}$ & $27^{\circ} 55.0^{\prime}$ & 18 & .26 & .70 & 51 & 59 \\
\hline $20 \mathrm{D}$ & $19^{\circ} 55.0^{\prime}$ & 24 & .18 & .70 & 54 & 67 \\
\hline $20 \mathrm{D}$ & $20^{\circ} \quad 2.5^{\prime}$ & 19 & .24 & .70 & 54 & 65 \\
\hline $10 \mathrm{D}$ & $10^{\circ} 20.1^{\prime}$ & 33 & .24 & .88 & 52 & 54 \\
\hline
\end{tabular}

On the basis of his experiments, Lenz derived a general formula for the coefficient of discharge

$$
C=0.560+\frac{M}{\mathbf{R}^{n} \mathbf{W}^{m}},
$$

in which $\mathbf{R}=\sqrt{\mathrm{g} h^{3}} /(\mu / \rho)$ is the Reynolds number; $\mathbf{W}=\left(\rho g h^{2}\right) / \sigma$, is the Weber number; and $M, n$, and $m$ are empirically determined functions of the notch angle,

$$
\begin{gathered}
M=0.475+\frac{0.225}{\left(\tan \frac{\theta}{2}\right)^{0.80}}, \\
n=0.165\left(\tan \frac{\theta}{2}\right)^{0.09},
\end{gathered}
$$

and

$$
m=\frac{0.170}{\left(\tan \frac{\theta}{2}\right)^{0.035}}
$$

That the formula is not truly general is indicated by the fact that strict limits of applicability were placed on $\mathbf{R}, \mathbf{W}, C$, and $\theta$.

For water at one temperature $\left(70^{\circ} \mathrm{F}\right)$, limits on $\mathbf{R}$ and $\mathbf{W}$ are removed, and $C$ can be computed with the equation

$$
C=0.560+\frac{N}{h^{a}},
$$

in which $N$ and $a$, like $M, n$, and $m$, are functions of $\theta$ alone. In equation $16, R$ and $\mathbf{W}$ are functions of the quantity $h$, because, for one liquid at a constant temperature, the fluid properties are constant (See the discussion leading to eq 4). Lenz gives experimentally determined values of $N$ and $a$ in table 3 . 
TABLE 3.-Values of $\mathrm{N}$ and a for equation 16 (Lenz)

\begin{tabular}{lcccccc}
\hline & \multicolumn{7}{c}{ Notch angle, $\theta$} \\
\cline { 2 - 7 } Constant & $90^{\circ}$ & $60^{\circ}$ & $45^{\circ}$ & $28^{\circ} 04^{\prime}$ & $20^{\circ}$ & $10^{\circ}$ \\
\hline$N$ & 0.0159 & 0.0203 & 0.0238 & 0.0315 & 0.0390 & 0.0624 \\
\hdashline & .588 & .582 & .579 & .575 & .573 & .569 \\
\hline
\end{tabular}

Basing his comparison on the tests of Barr, Yarnall, Greve, Ho and $\mathrm{Wu}$ (Ho and $\mathrm{Wu}, 1931)$, Lenz concluded that equation 16 would give results accurate to within 1 percent for all notch angles between $28^{\circ}$ and $90^{\circ}$. He observed that increasing the temperature of water from $40^{\circ} \mathrm{F}$ to $165^{\circ} \mathrm{F}$ decreases the computed value of $C$ about 1 percent.

\section{EXPERIMENTS OF NUMACHI, KUROKAWA, AND HUTIZAWA}

The most extensive investigation of a single notch angle and a single liquid is represented by the experiments performed by Numachi, Kurokawa, and Hutizawa (1940) at Tohoku Imperial University in Japan. These tests, all of which were made with water and a $90^{\circ}$ triangular-notch weir, covered a range of values of $h$ from 0.16 to 0.85 feet, $P$ from 0.31 to 2.16 feet, and $B$ from 1.44 to 3.87 feet. The channel in which the tests were made was 26 feet long and 3.87 feet wide. False walls and a false floor, extending 15 feet upstream from the weir, were used to produce 30 different values of $P / B$. The weir was made of bronze, and the weir crest surface was $5 / 64$ inches wide.

Subsequently, 12 additional series of tests were made by Numachi, Kurokawa, and Hutizawa (1943). Made with the same weir, these supplementary tests covered a lower range of values of $P$, from 0.01 to 0.164 feet. Values of $B$ varied from 0.985 to 2.10 feet. On the basis of their data, Numachi and Hutizawa proposed a general equation for the coefficient $C$,

$$
C=0.574+\frac{0.0055}{h}+\left(0.055+\frac{0.278}{0.886+P}\right)\left[\frac{h}{B}-\left(0.1-\frac{0.0098}{0.079+P}\right)\right]^{2} .
$$

Within the range of conditions covered by the tests, equation 17 gives results which are within 1 percent of the experimental data.

\section{OTHER EXPERIMENTS}

Among the many published accounts of experiments on triangularnotch weirs, some are of interest because they were especially concerned with certain details of the discharge characteristics. For example, Switzer (1915), Cozzens (1915), and Smith $(1934,1935)$ made tests 
to determine the influence of temperature on the discharge of water. On the basis of tests on $90^{\circ}$ and $54^{\circ}$ notches, with temperatures ranging from $39^{\circ} \mathrm{F}$ to $165^{\circ} \mathrm{F}$, Switzer concluded that the effect on the coefficient of discharge was less than 2 percent and "inappreciable compared with other factors present". Cozzens, on the other hand, presented a curve to be used to make a small correction over a range of temperatures from $60^{\circ} \mathrm{F}$ to $220^{\circ} \mathrm{F}$. Smith developed an empirical formula which incorporated the kinematic viscosity in a correction coefficient.

Professor H. W. King $(1916,1954)$ made tests on $90^{\circ}, 60^{\circ}$, and $22.5^{\circ}$ notches at the University of Michigan. His weirs were made of steel, with a sharp upstream crest edge and a crest-surface width of $1 / 8$ inch. The vertex of the notch was 2 feet above the floor of the experimental channel. On the basis of his experiments, Professor King developed the following formulas:

$$
\begin{gathered}
\left(90^{\circ} \text { notch }\right) C=\frac{0.589}{h^{0.03}}, \\
\left(60^{\circ} \text { notch }\right) C=0.595 h^{0.01}, \\
\left(22.5^{\circ} \text { notch }\right) C=\frac{0.586}{h^{0.07}},
\end{gathered}
$$

An investigation performed at Cornell University by Ho and $\mathrm{Wu}$ (1931) is notable for the large range of heads (from 0.129 to 3.43 ) covered by the tests. All of these tests were made in a channel 6 feet wide, 12 feet deep, and 30 feet long from baffles to weir plate. Weirs tested included notch angles of $90^{\circ}, 60^{\circ}, 37^{\circ}, 28^{\circ}$, and $19^{\circ}$. The vertices of notches were a minimum distance of 8 feet above the channel floor. The weir plates were made of galvanized sheet metal or brass, with sharp, square, upstream edges. Lenz (1943) observed that his general formula for water (eq 16) was confirmed within 1 percent by the Ho and Wu data.

From 1931 to 1934, four investigations were made at Princeton University by senior students under the direction of Professor L. F. Moody. Most pertinent of these is the investigation by Allerton (1932), which involved tests with notch angles of $90^{\circ}, 60^{\circ}, 54^{\circ}$, and $30^{\circ}$. Of particular interest is the fact that Allerton analyzed his data on the basis of a formula which involved a head adjustment similar to that used in equation 5 . The formula was attributed to Moody, but no mention of the formula is made in reports of two subsequent investigations made at Princeton.

Investigations which placed emphasis on the influence of viscosity were made by Mawson (1927), Thornton (1929), and Smith (1934, 1935). Because they ignored the equal or larger influence of surface tension, however, the results of the studies were inconclusive. 
Hertzler (1938) was especially concerned with $120^{\circ}$ notches. On the basis of his tests on six different weirs, all with $\theta=120^{\circ}$, he proposed the formula

$$
C=\frac{0.597}{h^{0.051}}
$$

\section{SUMMARY}

Published accounts of experimental investigations agree on very few details of the discharge characteristics of triangular-notch weirs. Some of the disagreements are doubtless the result of differences in equipment and technique. More significantly, however, conclusions drawn from the experiments are believed to differ because of certain inadequacies in traditional methods of analyzing the data.

It is reasonable to assume that experimental equipment was adequate and that the work was done with skill and care. Nevertheless, there are indications that some of the weirs were neither sharp-edged, thin-crested, nor smooth-faced. Crude equipment and technique in other instances resulted in systematic errors related to the measurement of $Q, h$, and $\theta$. The effect of these deviations cannot be determined from the information available.

There is some agreement that weirs with notch angles less than about $20^{\circ}$ or greater than about $100^{\circ}$ exhibit characteristics of instability which are related to the intermittent clinging of the nappe to the surface of the crest. Similar behavior was observed at extremely low heads on all notch angles.

Most investigators found that $C$ varied with notch angle. This is a clear indication of a shortcoming in the traditional, so-called theoretical equation of discharge (eq 1). Only one of the many investigations (by F. Numachi and others) included a systematic study of the influence of weir placement and channel geometry. However, this study was made with only one notch angle and one liquid. Several investigators demonstrated the practicality of using short approach channels if they are effectively equipped with baffles. No comprehensive studies have been made of the influence of velocity distribution and turbulence in the approach channel.

Few investigators attempted to isolate and evaluate the influence of the physical properties of the liquid, although several attempted to determine the effect of temperature on the discharge of one liquid (water). Their conclusions are remarkable for their disagreement. Lenz made considerable progress in isolating the separate effects of viscosity and surface tension, but the range of conditions covered in the investigation was quite limited. For this reason, his proposed general formulas are restricted in applicability. They are also inconvenient to use. 
Most investigators working with water at normal temperatures reported a correlation between $C$ and $h$. Empirical formulas were evolved to account for this correlation, but no explicit recognition was given to the fact that the $h$ correlation is evidence of the combined effects of viscosity and surface tension. Thus, the "scale effect" implications of the phenomenon were ignored. It is believed that the effectivehead concept (eq 5) provides a reasonable and practical method of accounting for the effects related to the absolute magnitude of $h$.

No additional experiments were made for this investigation. Instead, experimental data obtained from some of the sources reviewed above are used in the following analysis.

\section{ANALYSIS OF DATA}

\section{EVALUATION OF $k_{h}$}

The coefficient $C_{e}$ in equations 6 and 7 is described as a function of geometric ratios $(h / P, P / B$, and $\theta)$ when $h_{e}$, the "effective head," is determined from equation 5 ,

$$
h_{e}=h+k_{h} \text {. }
$$

In this equation, $h$ is the measured head on the notch and $k_{h}$ is an experimentally determined quantity that accounts for the combined effects of viscosity and surface tension. Comparison of equations 4 and 7 shows that the effect of the effective-head adjustment is to relieve the coefficient of discharge of dependency on $h$. This criterion is used to determine the value of $k_{h}$ which is applicable to a specific set of experimental data. For one liquid over a small temperature range, and for one notch angle, $k_{h}$ is assumed to be a constant.

The validity of the several basic assumptions related to the effective head concept has been demonstrated in a previous study of rectangular weirs. Nevertheless, the practicality of the concept as applied specifically to triangular-notch weirs must be established on the basis of experimental data for triangular-notch weirs. The results of experiments by Barr, Cone, Yarnall, Greve, Lenz, and Numachi, Kurokawa, and Hutizawa are selected for this purpose. Because the flow of water at ordinary atmospheric temperatures is of principal interest to the Geological Survey, and because data on other liquids are limited in many ways, the data used are only those which involve water in the temperature range from $40^{\circ} \mathrm{F}$ to $85^{\circ} \mathrm{F}$.

In the validation process, the quantity $k_{h}$ is evaluated from experimental data by a trial procedure. For a series of tests in which $h$ is the principal variable, $k_{h}$ is determined by successive approximations as the quantity which will remove the correlation between $C$ and $h$. The 


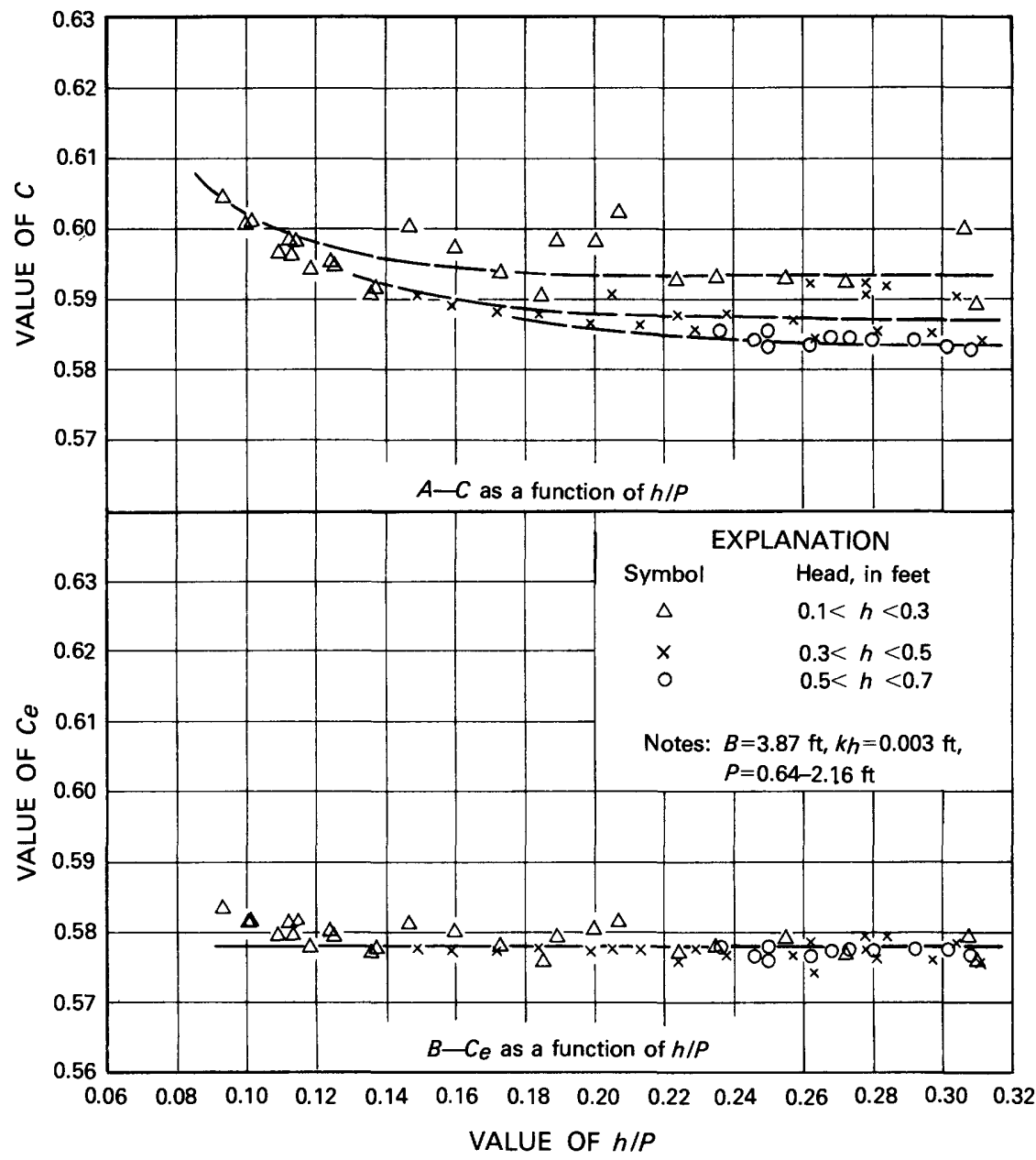

FIgURE 2.-Evaluation of $k_{h}$ illustrated with Numachi, Kurokawa, and Hutizawa data $\left(\theta=90^{\circ}\right)$.

procedure is illustrated in figure 2 by its application to some of the data reported by Numachi, Kurokawa, and Hutizawa. ${ }^{3}$ These data were selected because they were obtained with different values of $P$. Thus, the influence of $h$ can be isolated from the influence on $h / P$. The tests shown in figure 2 are for a constant, large value of $B$ and 5 different values of $P$, all with a $90^{\circ}$-notch weir. Figure $2 A$ shows $C$ plotted as a function of $h / P$. Ranges of values of $h$ are indicated by the symbols shown in the legend. The scatter in values of $C$ is systematically related

\footnotetext{
${ }^{3}$ The procedure is illustrated and discussed in greater detail in the paper by Kindsvater and Carter (1959, p. $783-787$, figs. $3,4,5,6$ ) on rectangular weirs.
} 
to the magnitude of $h$ as shown by the dashed curves. There is no clearly defined correlation with $P$. Figure $2 B$ shows $C_{e}$ plotted as a function of $h / P$. The value of $k_{h}$ which was used in the computations of $C_{e}$ for this figure was 0.003 foot. Evidence of the lack of correlation between $C_{e}$ and $h$ is shown by the fact that one curve drawn through all the points is horizontal, and the scatter is greatly reduced. Thus, the validity of the effective-head concept is demonstrated, and the value $k_{h}=0.003$ foot is shown to be appropriate for the tests by Numachi and others.

Another demonstration of the validation procedure is shown in figure 3 , which is based on the results of Lenz's tests on weirs with three

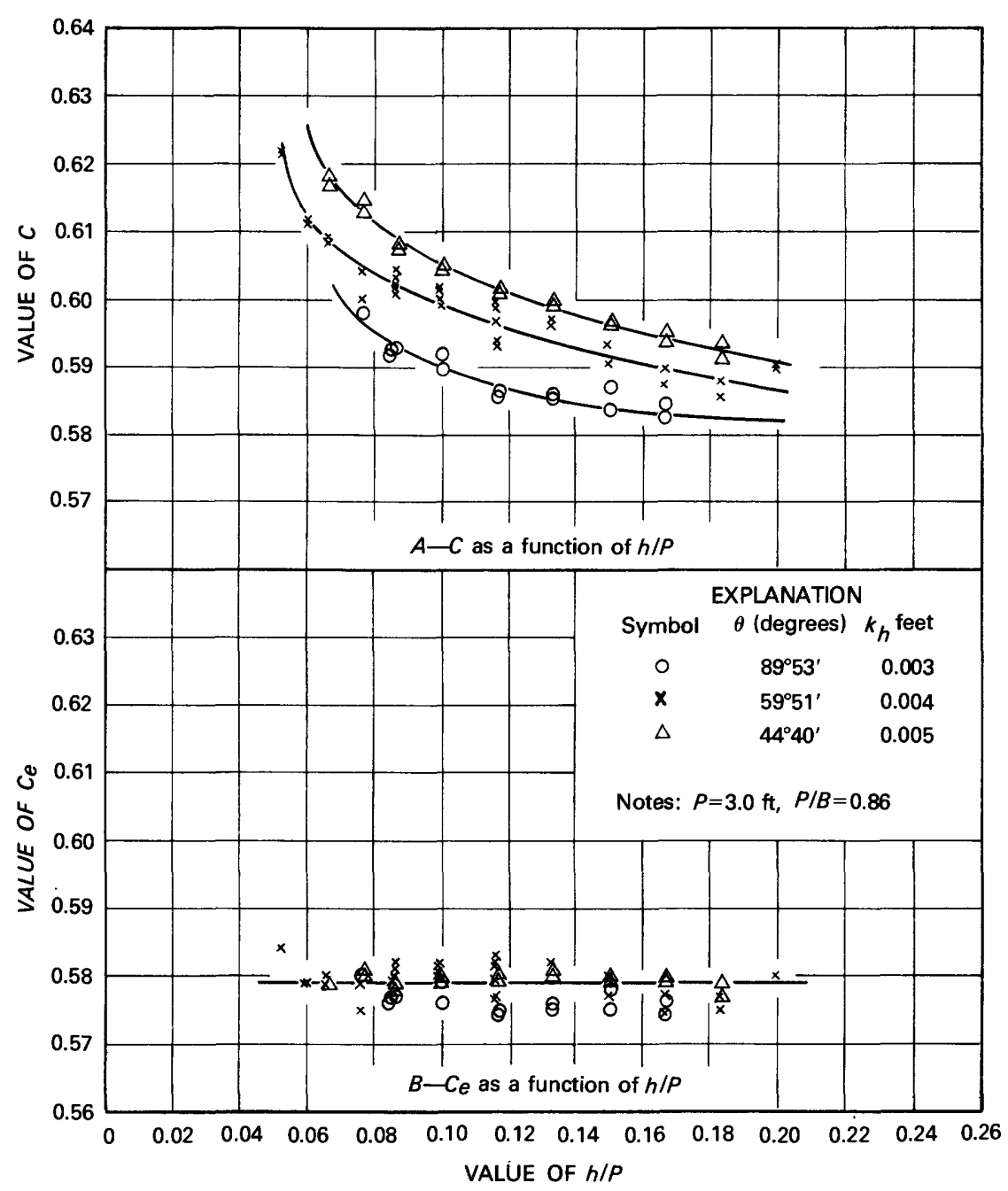

Figure 3.-Evaluation of $k_{h}$ illustrated with Lenz data. 
different notch angles. Values of the notch angles are shown in the legend. In the top part of figure $3, C$ is plotted as a function of $h / P$, but because $P$ is constant for each weir, the separation and curvature of the lines drawn through the plotted points show the influence related to $h$ and $\theta$.

The lower part of figure 3 shows $C_{e}$ plotted as a function of $h / P$ for the Lenz data. In this instance, different values of $k_{h}$ were derived for each value of $\theta$, as shown in the legend. Here again the effectiveness of $k_{h}$ in eliminating $h$ as an independent variable is demonstrated by the fact that curves drawn through the points are essentially horizontal. Coincidentally, a single curve fits the three sets of points reasonably well, showing that $\theta$ has a minimal effect on $C_{e}$ for notch angles between $45^{\circ}$ and $90^{\circ}$. Values of $P / B$ and $h / P$ represented by the tests shown in figures 2 and 3 are in the range in which these variables also have negligible influence on $C_{e}$. This fact is demonstrated subsequently.

Values of $k_{h}$ for values of $\theta$ between $10^{\circ}$ and $120^{\circ}$ were determined from the tests made by Barr, Cone, Yarnall, Greve, Lenz, and Numachi and others. The results are shown on figure 4. Values of $k_{h}$ for those few tests which were made for very small or very large notch angles are not well defined. Deviations from the smooth curve drawn through the points can be attributed to differences in physical characteristics of weirs and test channels.

\section{AN ALTERNATIVE FOR $\boldsymbol{k}_{h}$}

The quantity $k_{h}$ is added to the measured head as an adjustment for the combined effects of viscosity and surface tension. The procedure is justified with the observation that, in general, the effects of the two fluid properties are commensurate with a fictitious increase in head and notch width. Because the width is a function of the head for triangularnotch weirs, a quantity added to the head is simultaneously an adjustment of the width. However, because the width is a function of $\theta$ as well as $h$, it is not unreasonable that figure 4 shows $k_{h}$ to be a function of $\theta$.

As an alternative to $k_{h}$, a factor $k$ is proposed, where $k$ is measured perpendicularly to the sides of the notch. Thus,

$$
k=k_{h} \sin \frac{\theta}{2} .
$$

Values of $k$ were computed for the data shown in figure 4 to determine whether $k$ might be constant for all notch angles. The results are shown in figure 5. The figure shows that a value of $k=0.002$ foot could be used for values of $\theta$ between $40^{\circ}$ and $90^{\circ}$. Somewhat smaller values of $k$ are indicated for values of $\theta$ less than $40^{\circ}$. The quantity $k$ is not well defined for values of $\theta$ greater than $90^{\circ}$. 


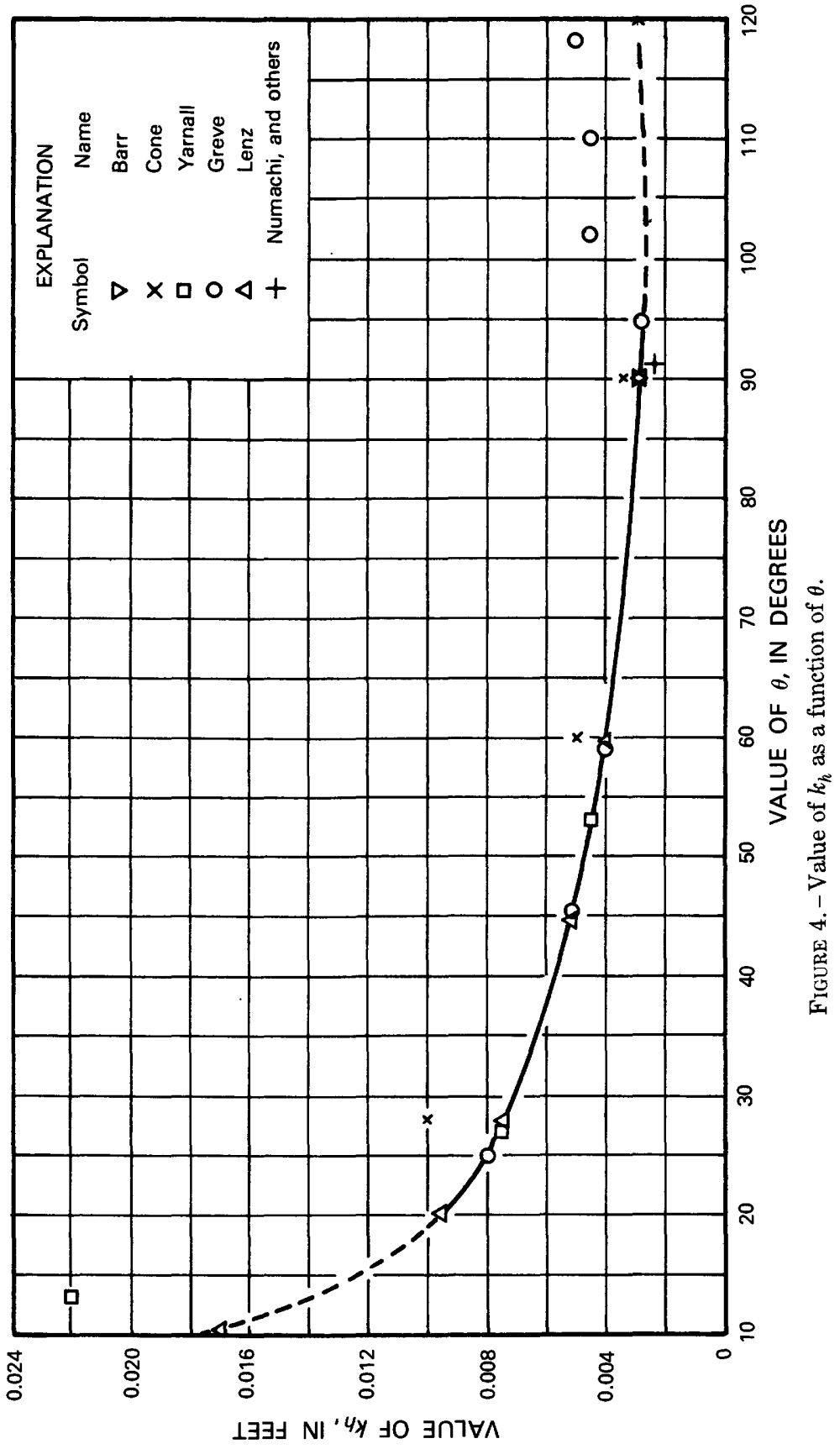




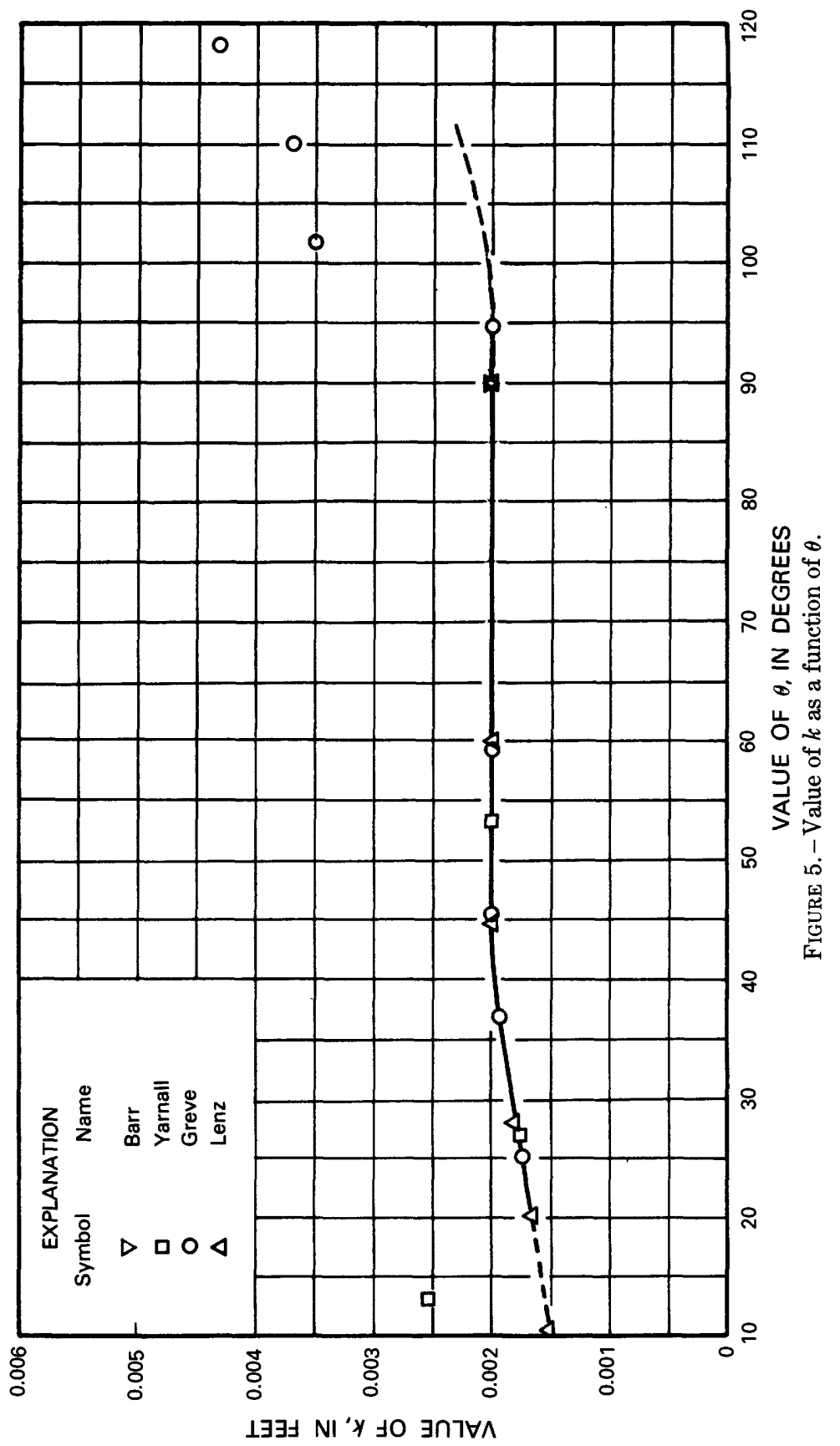


It is apparent that the effective head in the modified basic equation of discharge (eq 6) can be evaluated in terms of either $k$ or $k_{h}$. If $k_{h}$ is used, values of $k_{h}$ are read from figure 4 . If $k$ is used, values of $k$ can be read from figure 5 , or, in the range from $40^{\circ}$ to $90^{\circ}, h_{e}$ can be computed as

$$
h_{e}=h+\frac{0.002}{\sin \frac{\theta}{2}} \text {. }
$$

Which of these alternatives is the more convenient is conjectural. Hereafter in this report, $h_{e}$ is computed with values of $k_{h}$ from figure 4.

\section{EVALUATION OF $C_{e}$}

Figures 6 to 11, inclusive, show values of $C_{e}$ computed from results of the tests by Barr, Cone, Yarnall, Greve, Lenz, and Numachi, Kurokawa, and Hutizawa. In the figures, $C_{e}$ is plotted as a function of $h / P$. The data cover a long range of notch angles from $120^{\circ}$ to $10^{\circ}$. Included on each figure is a legend which identifies the investigators and gives corresponding values of $\theta, P / B$, and $k_{h}$. Values of $k_{h}$ used in computing $C_{e}$ for each set of tests are the values plotted in figure 4 . The average values of $C_{e}$ were determined visually by fitting a line to the plotted points. The average value and the limits representing 1 percent deviations from the average are shown as horizontal lines in each figure.

The experimental data plotted in figures 6 through 11 show a range of values of $h / P$ from 0.03 to 0.35 and a range of values of $P / B$ from 0.15 to 1.5. In this range, which includes the most common limits for practical applications, it is apparent that $C_{e}$ is virtually independent of $h / P$ and $P / B$. Thus, within this range $C_{e}$ is remarkably well defined as a function of $\theta$ alone. Scatter in the test points at smaller values of $h / P$ is attributed to the influence of intermittent nappe-clinging at small values of $h$. The influence of $P / B$ at higher values of $h / P$ is discussed in the next section.

Figure 12 shows the relationship between $\theta$ and the average values of $C_{e}$ determined from figures 6 through 11. The dashed portions of the summary curves for $C_{e}$ (fig. 12) and $k_{h}$ (fig. 4) indicate that there is some uncertainty regarding the practicality of weirs with notch angles less than $20^{\circ}$ or greater than $100^{\circ}$. 


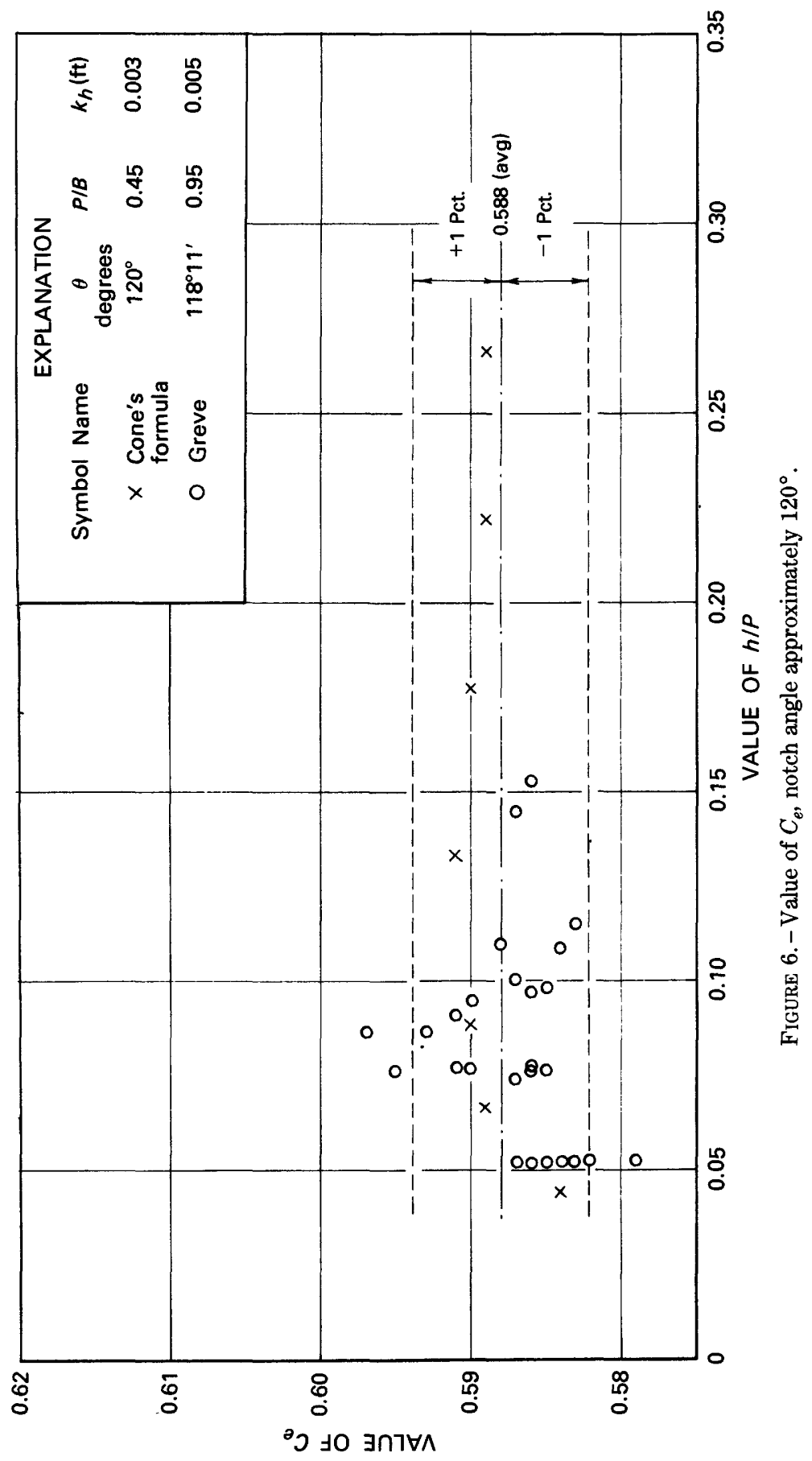




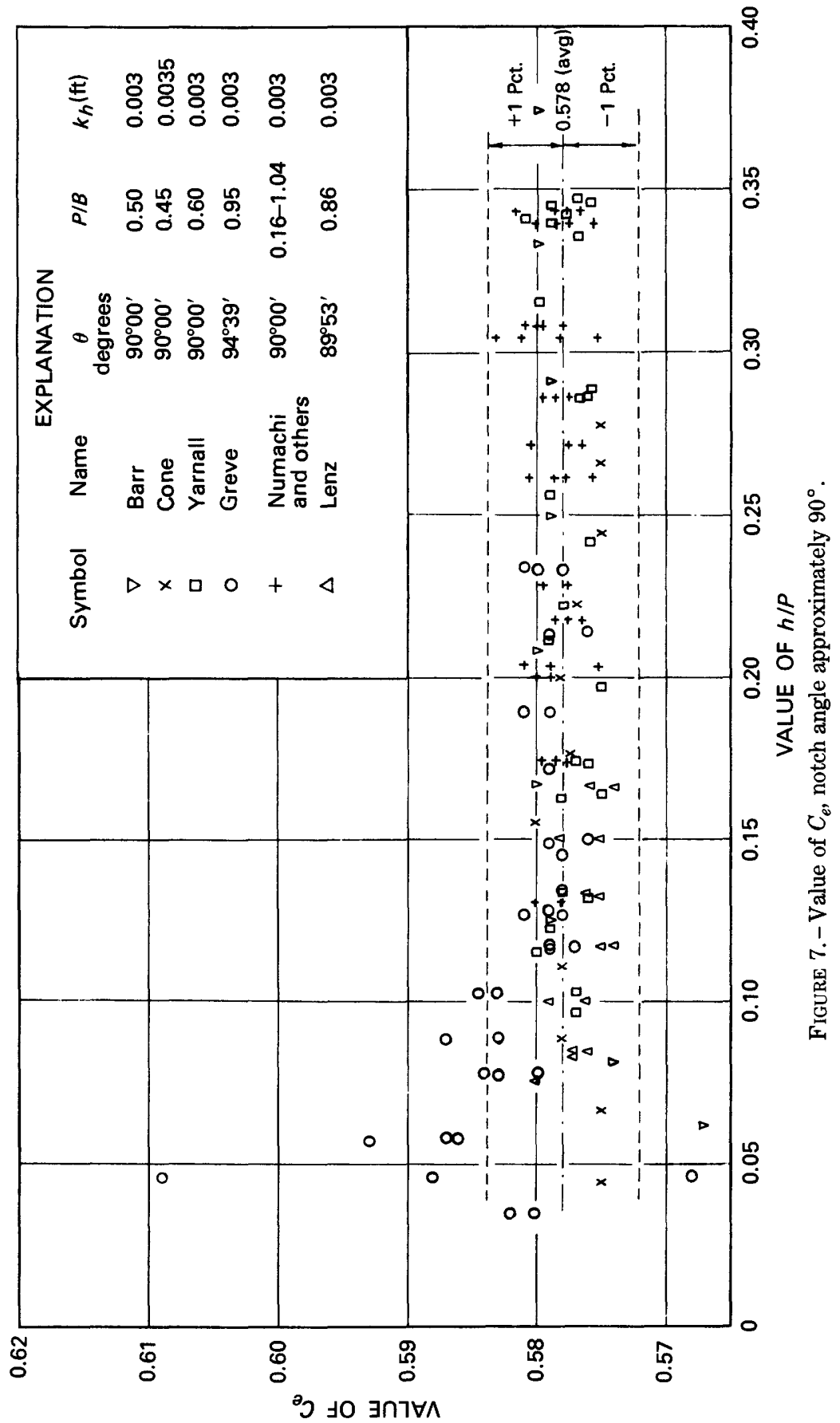




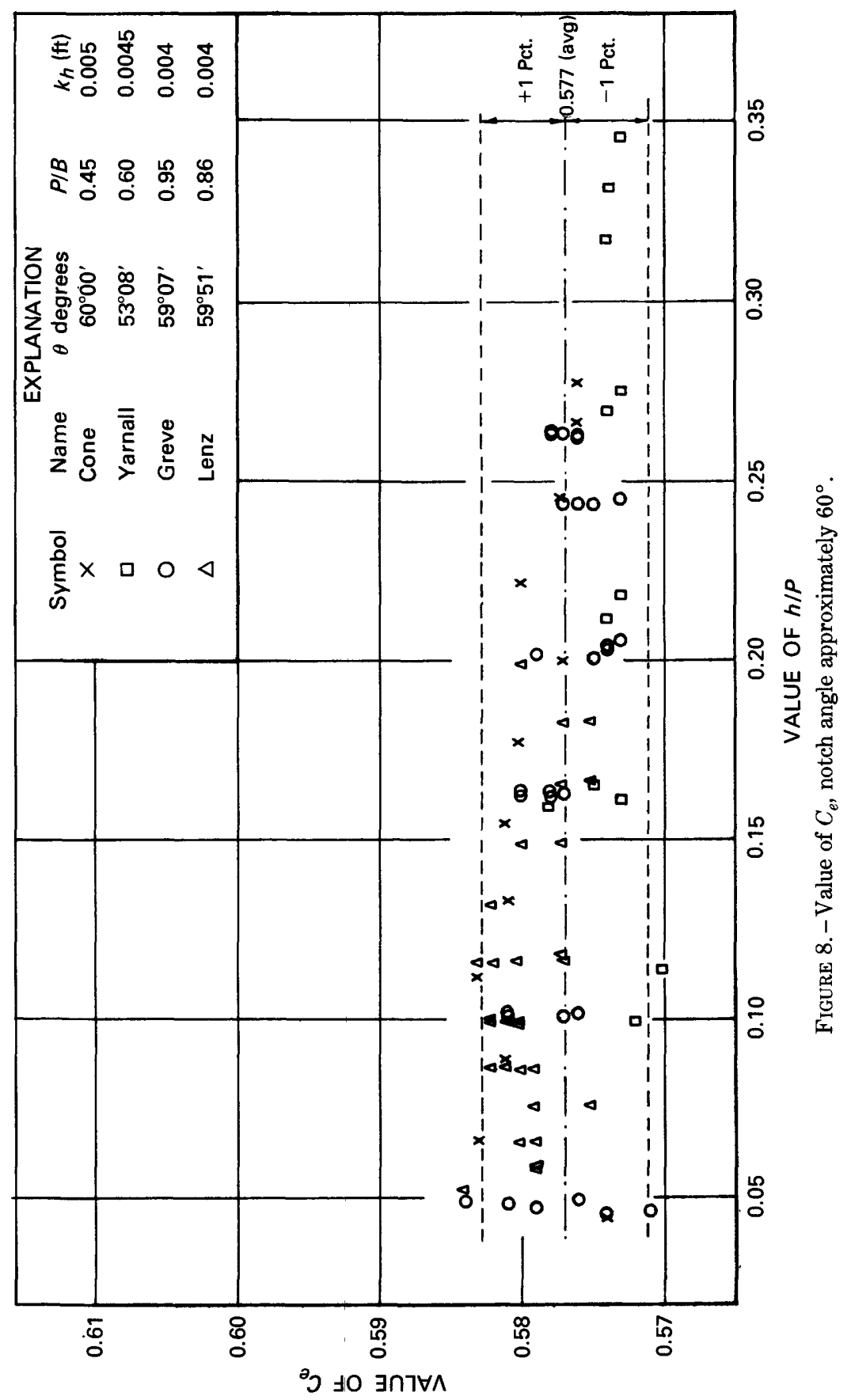




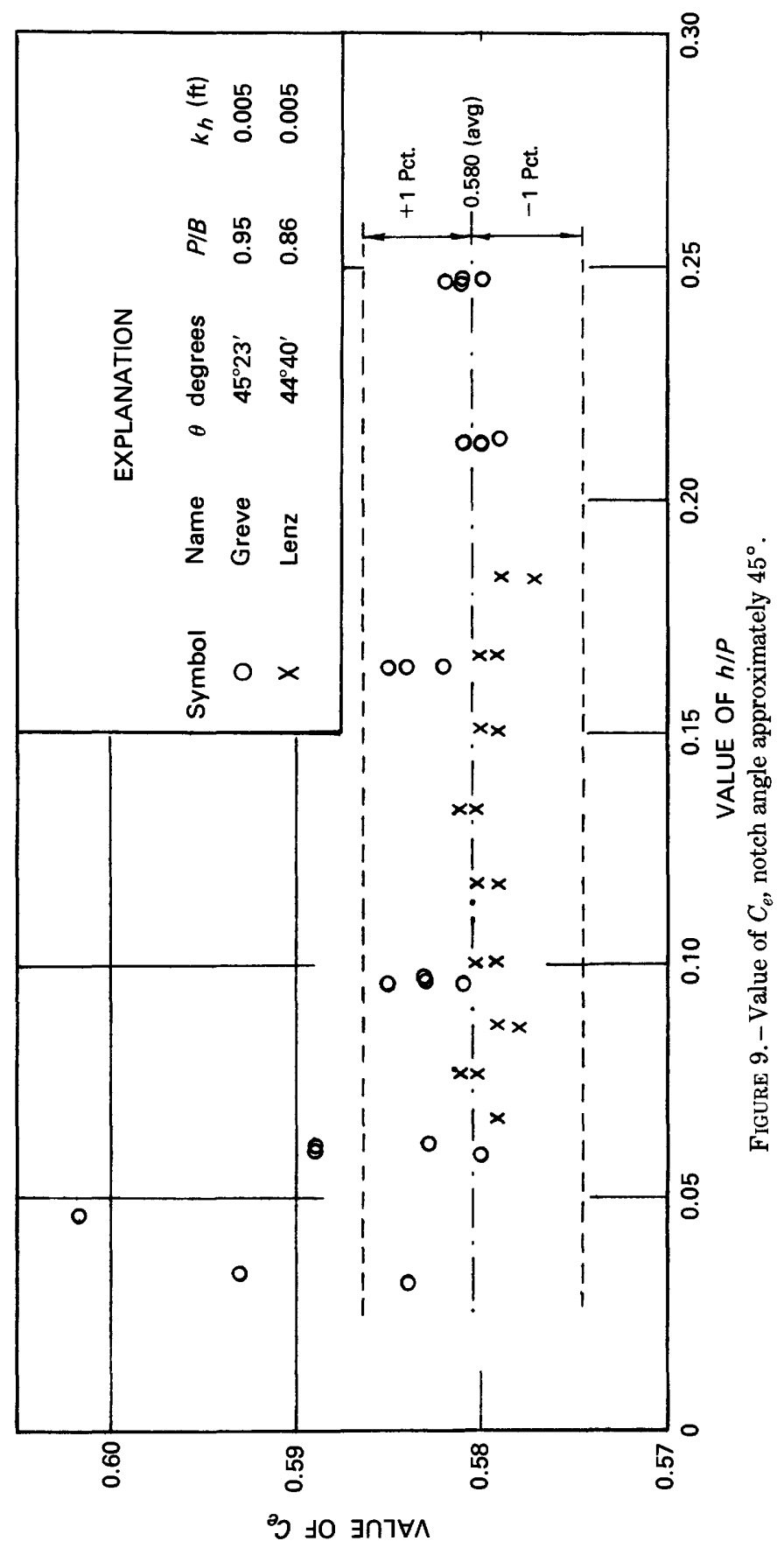




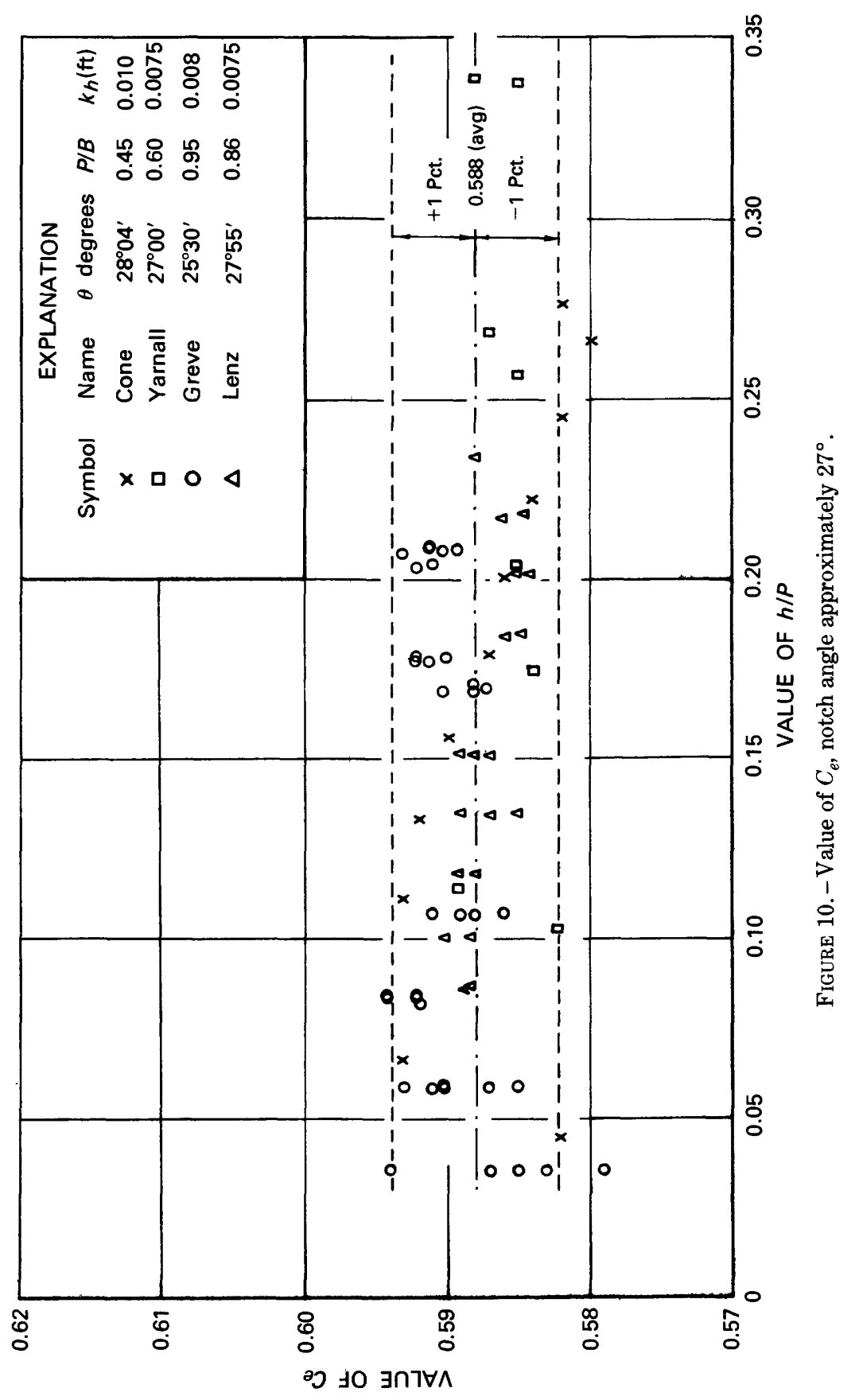




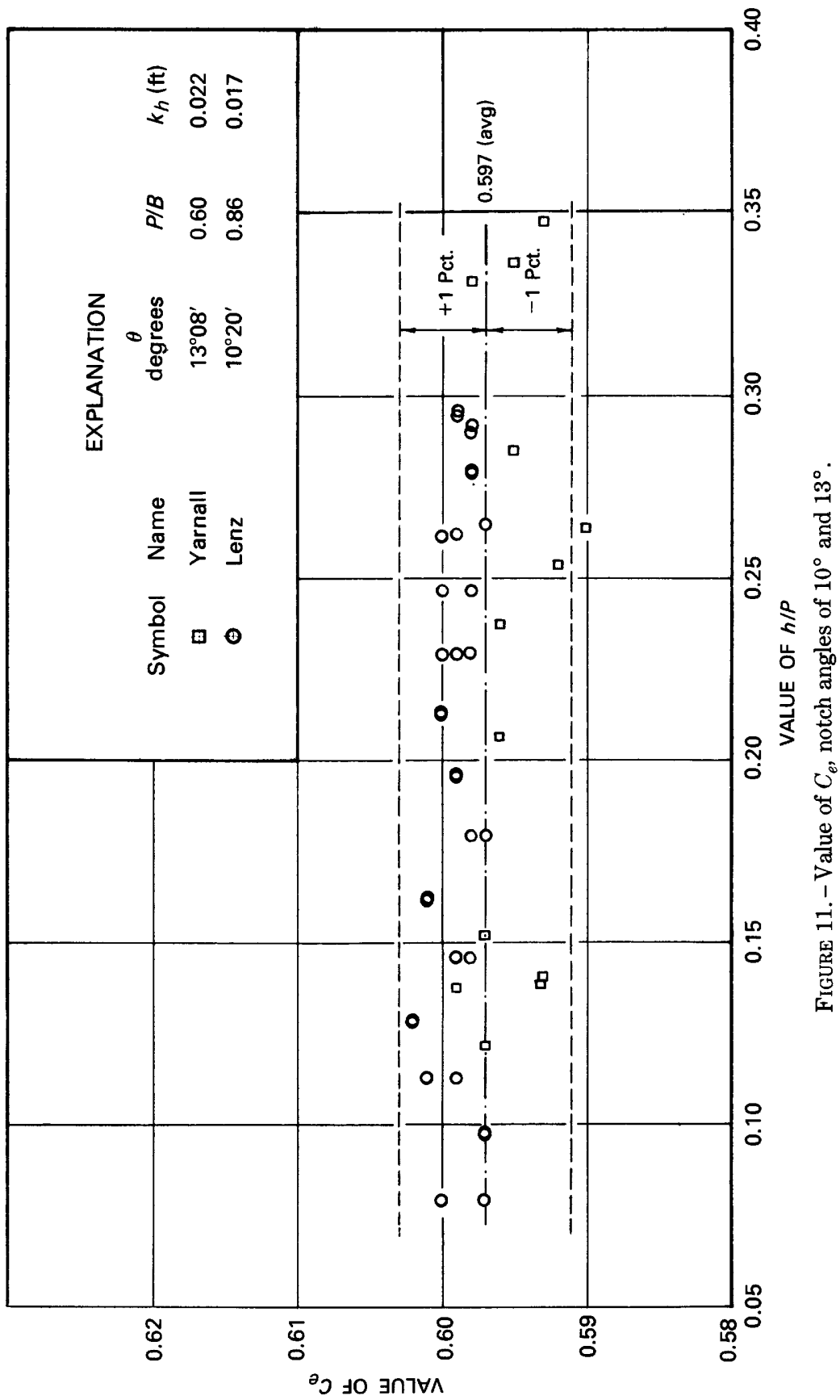




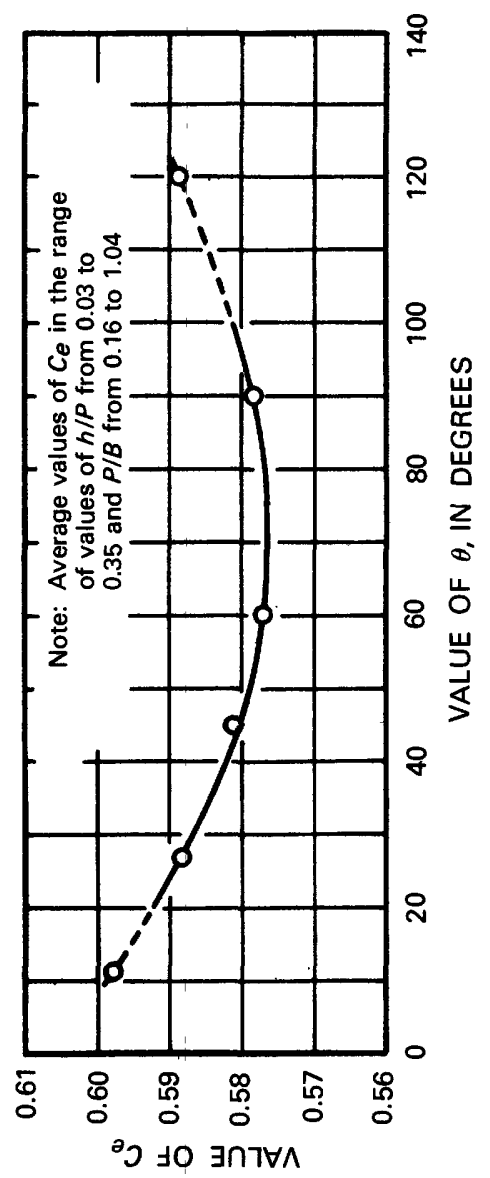




\section{INFLUENCE OF $h / P$ AND $P / B$}

A few tests involving different values of $P$ and $B$ were made by Barr, and some tests with $P=0$ were reported by Thomson and Cone. Among the experimental data available to the writer, however, the only data covering an extensive range of values of $h / P$ and $P / B$ were those obtained from the experiments on $90^{\circ}$ notches made by Numachi, Kurokawa, and Hutizawa.

Values of $C_{e}$ were computed from the results of the NumachiKurokawa-Hutizawa tests, using $k_{h}=0.003$ foot. Smooth curves interpolated from the plotted data were cross-plotted to obtain the family of curves showing $C_{e}$ as a function of $h / P$ and $P / B$ on figure 13 . The results are a comprehensive solution for $90^{\circ}$-notch weirs that, because of the degree of extrapolation from the data, must be regarded as unsubstantiated. The $h / P$ limit lines at the lower left corner of figure 13 illustrate the limited $h / P$ range of the Numachi-Kurokawa-Hutizawa tests, and the $C_{e}$ values from those tests, plotted in figure 7 , are all within 1 percent of the average value (0.578).

\section{COMPARISON OF FORMULAS}

\section{BASIS OF COMPARISON}

Derived from tests in which $h / P$ and $P / B$ were of negligible significance, the traditional formulas for triangular-notch weirs are generally of the form

$$
C=f(\theta, h),
$$

in which an empirically derived term involving $h$ accounts for the combined effects of viscosity and surface tension for water at ordinary temperatures. Unfortunately, the significance of $h$ was not understood by the originators of most of these formulas. Consequently, the more conservative investigators specified a range of applicability which was based on the limits of their test conditions.

In order to compare the proposed new formula (eq 6) with the classic formulas, values of $C$ were computed from the classic formulas and from the equation,

$$
C=\left(\frac{h+k_{h}}{h}\right)^{5 / 2} C_{e}
$$

obtained from the solution of equations 1 and 6 .

Values of $C_{e}$ and $k_{h}$ were obtained from figures 10 and 4, respectively. The comparisons are shown in figures 14-19, inclusive, in which $C$ is shown as a function of $h$ for selected values of $\theta$. 


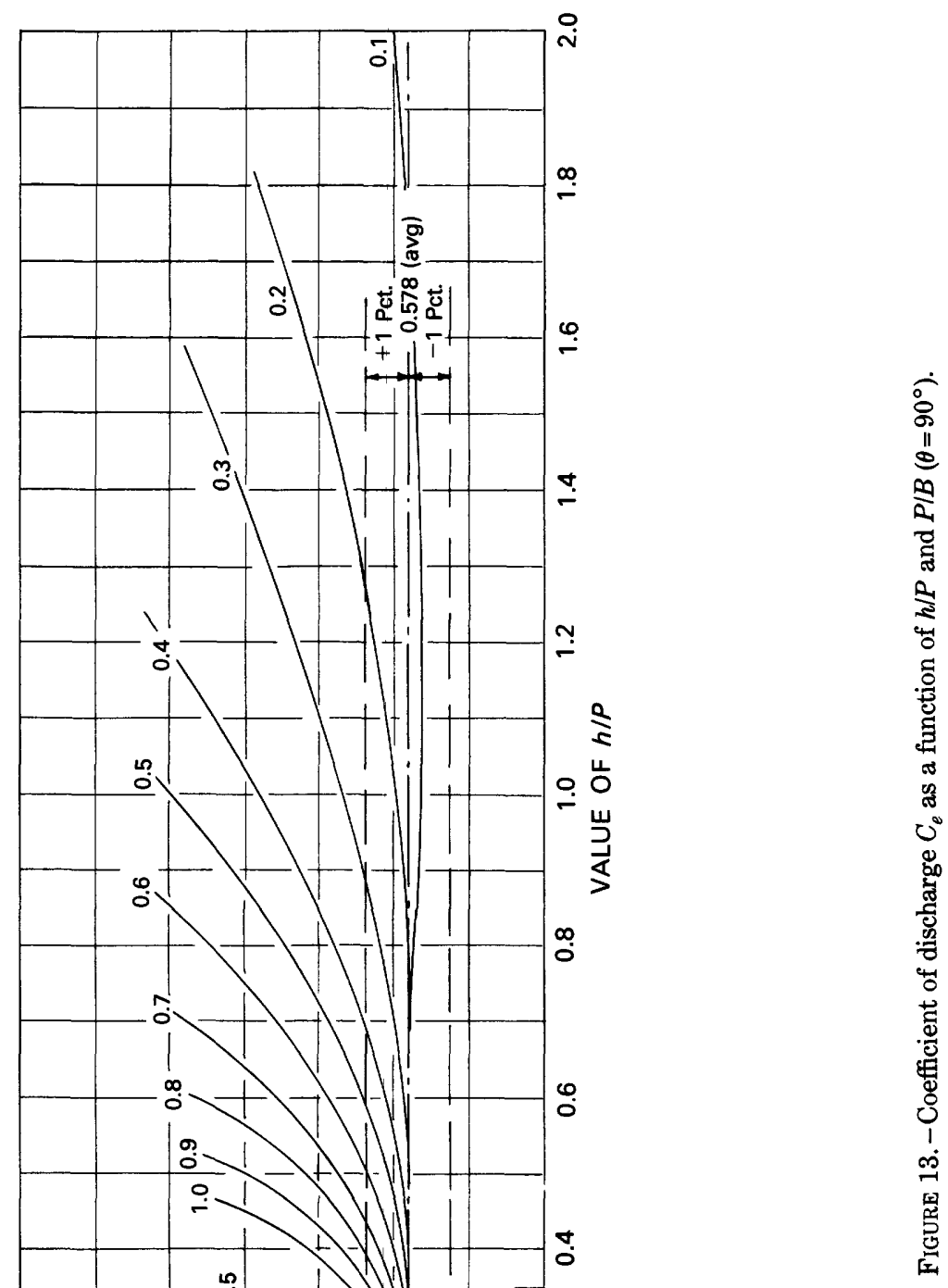




\section{0'-NOTCH WEIR}

The most frequently used triangular-notch weir is one with a notch angle of $90^{\circ}$. Some of the classic formulas are intended for use with this weir alone. Figure 14 shows a comparison of values of $C$ computed from the well-known formulas of Thomson, Barr-Strickland (eq 8), Cone (eq 9, 10), Greve (eq 11), Lenz (eq 16), and King (eq 18) and the formula determined from equation 25 in combination with figures 12 and 4 . The Thomson "formula" is actually just $C=0.593$, because Thomson did not propose a correlation with $h$.

It is emphasized that figure 14 is a comparison of formulas, whereas figure 7 is a comparison of the data from which the formulas were derived. Thus, the disagreement shown in figure 14, especially at small values of $h$, is to a large degree evidence of inadequacies of the formulas as representations of the data on which they were based. Figure 7 shows that the source data for all the formulas agree remarkably well in defining $C_{e}$ for use in equation 6 .

\section{OTHER NOTCH ANGLES}

Figures 15 through 19 show comparisons of well-known formulas for weirs with $120^{\circ}, 60^{\circ}, 45^{\circ}, 27^{\circ}$, and $10^{\circ}$ notch angles. The solid line in each figure was computed from equation 25 , with values of $C_{e}$ and $k_{h}$ from figures 12 and 4, respectively. The corresponding comparisons of experimental data are shown in figures 6 and 8 through 11 . It is demonstrated again that the solution derived from the effective-head concept is substantiated by the experimental data, whereas the classic formulas show justifiable differences at small values of $h$.

\section{CONCLUSIONS}

The triangular-notch, thin-plate weir is potentially an accurate, convenient means of measuring the flow of liquids. Classic discharge formulas are inadequate, however, because they fail to recognize the full significance of the pertinent variables. Although the triangular-notch weir is not subject to a completely analytical solution, available experimental data are sufficient to substantiate a practical solution which is based on dimensional analysis and experimental coefficients. Limitations of the data restrict the use of the solution to water.

The equation of discharge proposed in this report is

$$
Q=C_{e} \frac{8}{15} \sqrt{2 \mathrm{~g}} \tan \frac{\theta}{2} h_{e}^{5 / 2}
$$

in which $h_{e}$, the effective head, is defined by the equation

$$
h_{e}=h+k_{h} \text {, }
$$

and values of $k_{h}$ are shown in figure 4 . 


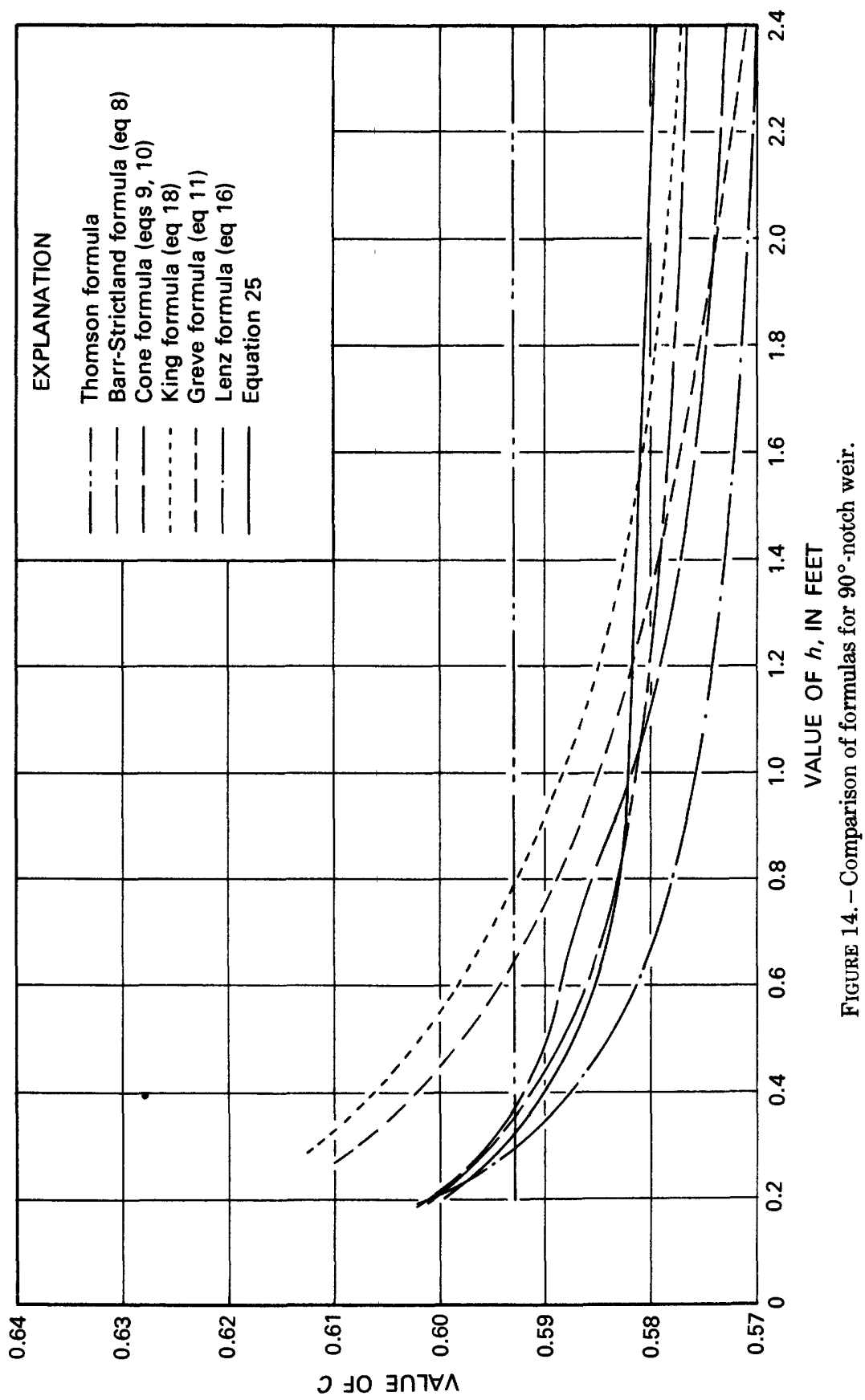




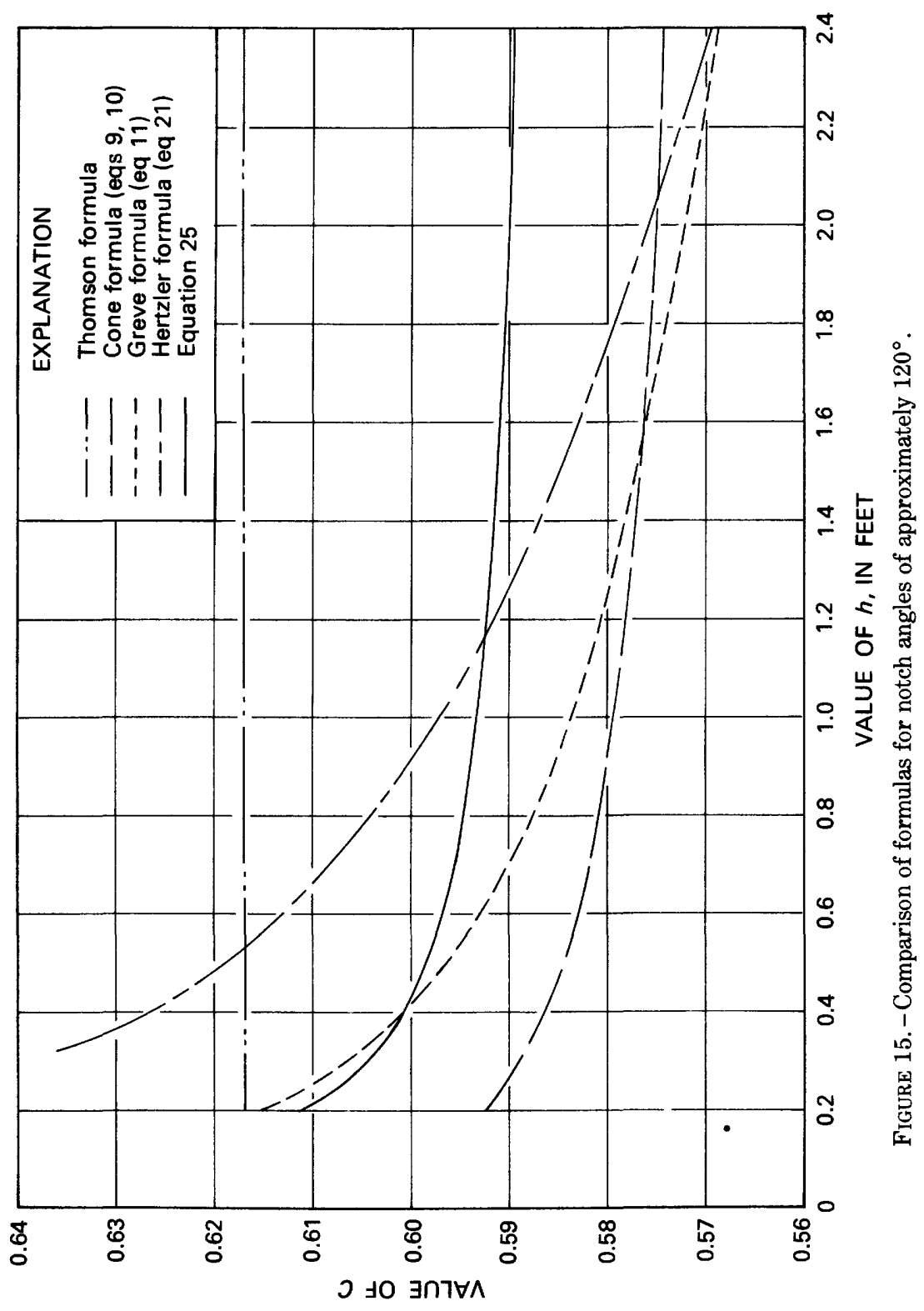


DISCHARGE OVER TRIANGULAR-NOTCH THIN-PLATE WEIRS B35

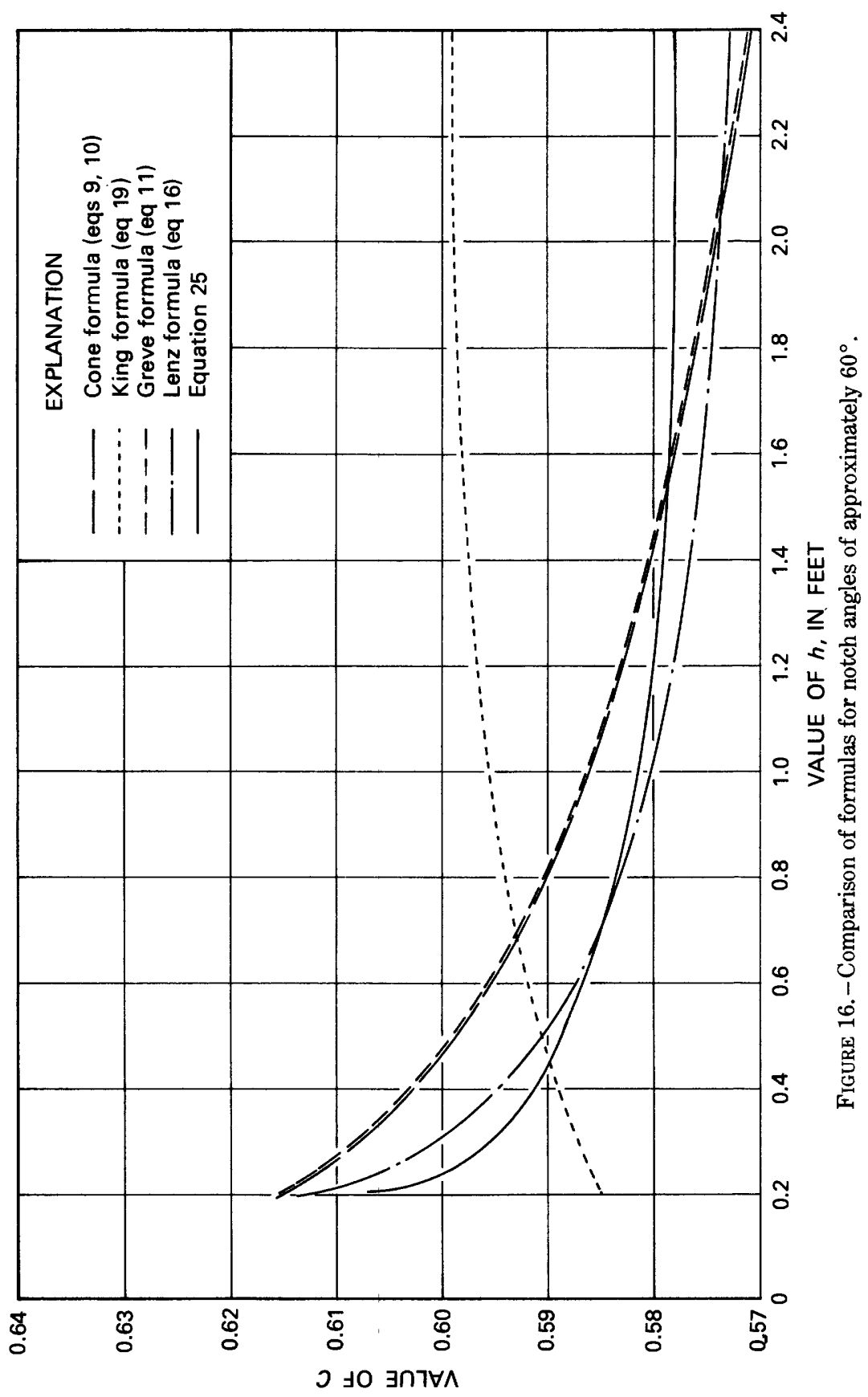




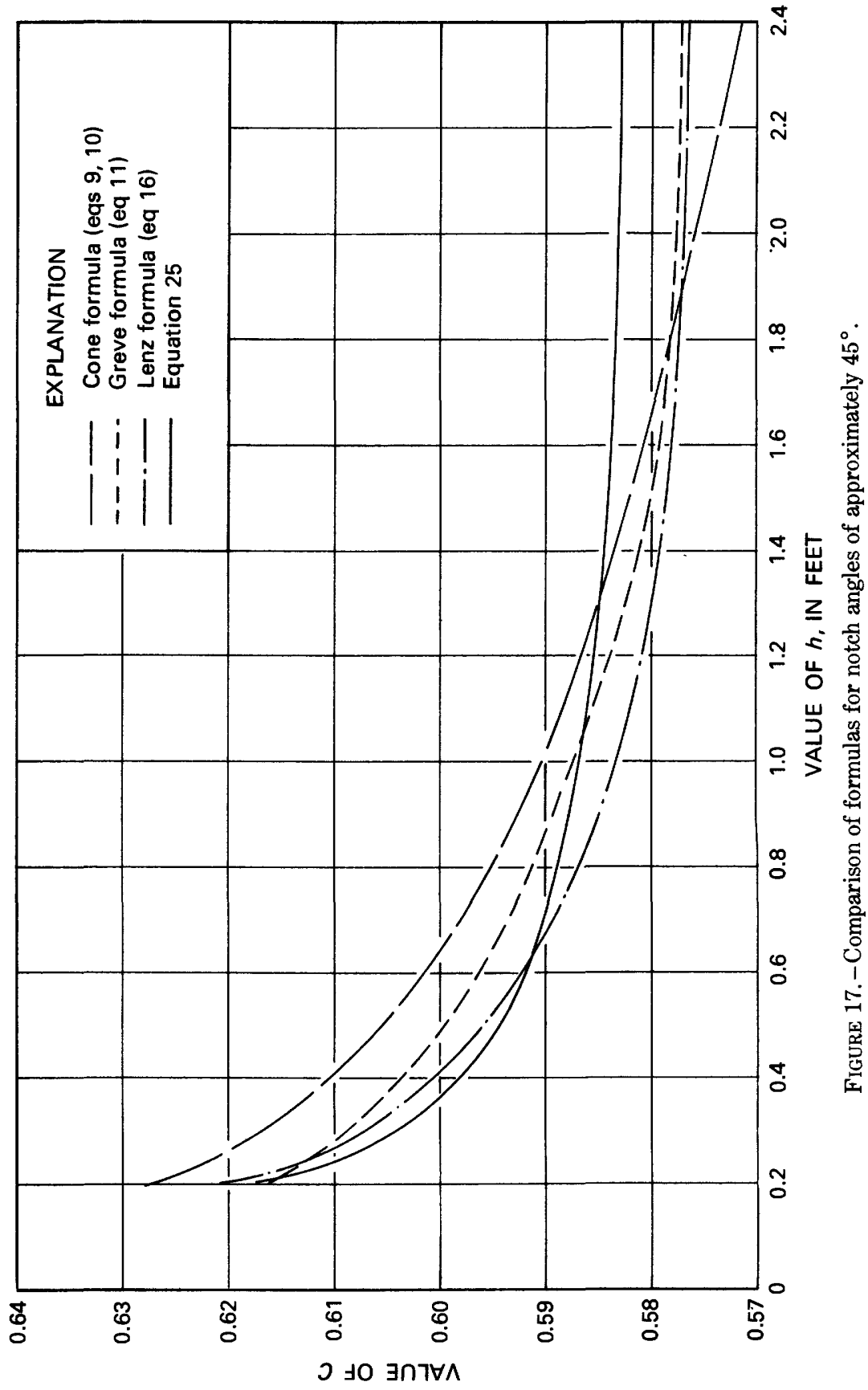




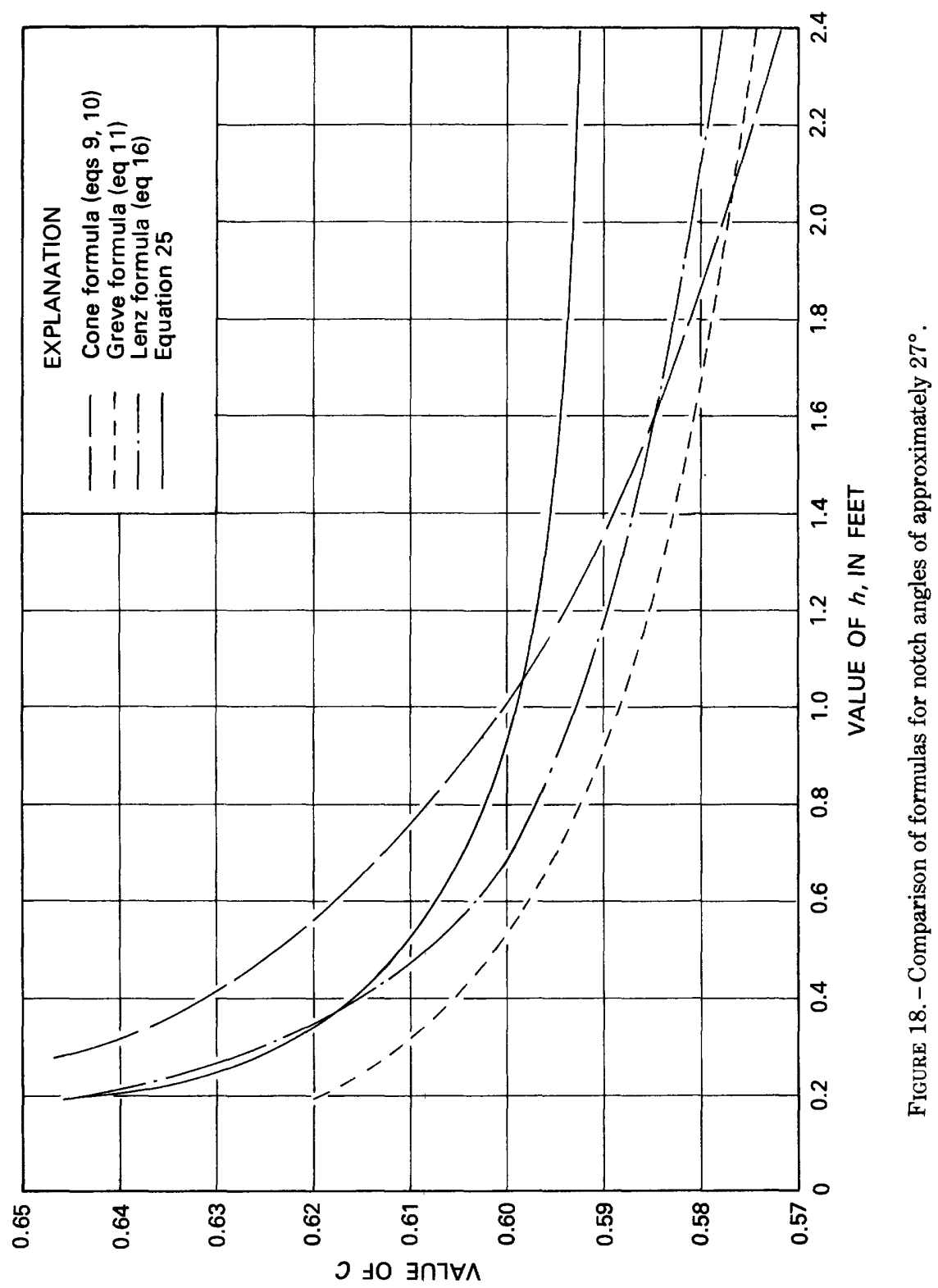




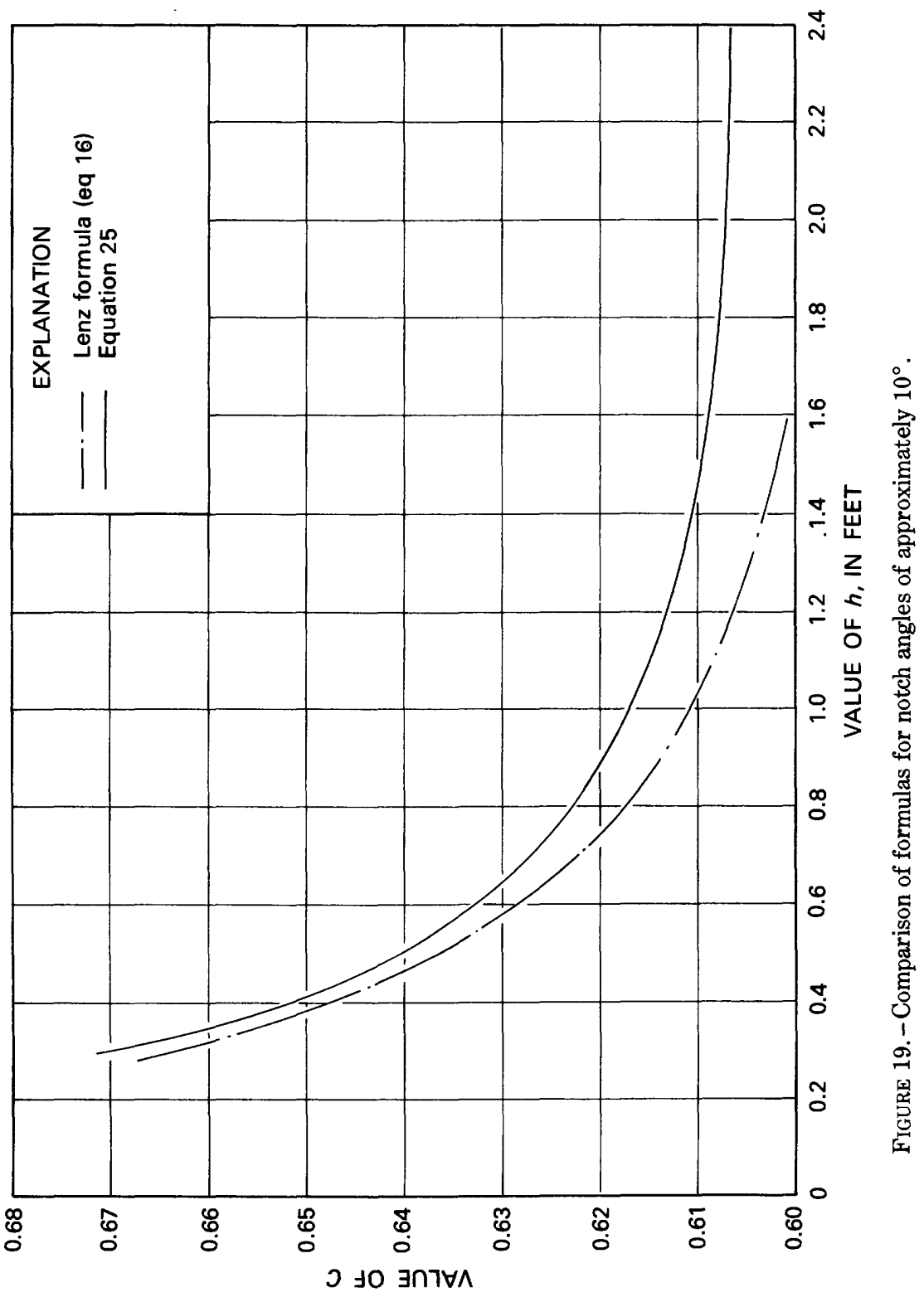


In general, the coefficient of discharge, $C_{e}$, is an experimentally determined function of the geometric parameters $h / P, P / B$, and $\theta$. However, within the range of the most common practical limits of $h / P$ and $P / B, C_{e}$ is a function of $\theta$ alone (fig. 12). In this range, values of $C_{e}$ computed from the results of experiments by Barr, Cone, Yarnall, Greve, Lenz, and Numachi, Kurokawa, and Hutizawa show remarkable agreement. For $\theta=90^{\circ}$ the available data are sufficient to define $C_{e}$ over a wider range of values of $h / P$ and $P / B$ (fig. 13).

\section{REFERENCES}

Allerton, R. W., 1932, Flow of water over triangular weirs: Princeton University, Thesis (mech. eng.), 56 p. 29 figs.

Barr, James, 1910, Experiments upon the flow of water over triangular notches: Engineering (London), v. 89, (April 8 and 15), p. $435 \mathrm{ff}$.

Burgess, J. S., and White, W. R., 1966, The triangular-profile (Crump) weir-two-dimensional study of discharge characteristics, Hydraulics Research Station (Wallingford, U.K.), HRS Report INT 52.

Carter, R. W., 1956, A comprehensive discharge equation for rectangular-notch weirs, Master's thesis, Georgia Institute of Technology.

Cone, V. M., 1916, Flow through weir notches with thin edges and full contractions: U.S. Department of Agriculture, Journal of Agricultural Research, v. V, no. 23 (March 6), p. 1051.

Cozzens, H. A., Jr., 1915, Flow over V-notch weirs: Power, v. 42, no. 21 (November 23), p. 714.

Greve, F. W., 1932, Flow of water through circular, parabolic, and triangular verticalnotch weirs: (Purdue Univ., Eng. Bull., v. XVI, no. 2, Research Series No. 40 (March), 84 p., 15 figs.

Hertzler, R. A., 1938, Determination of a formula for the $120^{\circ}$ V-notch weir: Civil Eng. (November), p. 756.

Ho, Chitty, and Wu, S. L., 1931, The flow of water over sharp crested weir notchesrectangular, trapezoidal, and triangular: Cornell Univ., Master's thesis, 155 p., 78 figs.

International Standards Organization, 1975, Liquid flow measurement in open channels using thin-plate weirs and venturi flumes (ISO 1438-1975).

Kindsvater, C. E., and Carter, R. W., 1959, Discharge characteristics of rectangular thin-plate weirs: Am. Soc., Civil Engineers Trans., v. 124, p. 772.

Kindsvater, Carl E., 1964, Discharge characteristics of embankment-shaped weirs: U.S. Geol. Survey Water-Supply Paper 1617-A, 114 p., 57 figs.

King, H. W., 1916, Flow of water over right-angled V-notch weir: Univ., Michigan Technic, v. 29, no. 3 (October), p. 189.

1954, Handbook of Hydraulics (Revised by Ernest F. Brater): New York, McGraw-Hill Book Co., 567 p., 165 figs.

Lenz, A. T., 1943, Viscosity and surface tension effects on V-notch weir coefficients: Am. Soc. Civil Engineers Trans., v. 108, p. 759.

Mawson, Humbert, 1927, Applications of the principles of dimensional and dynamical similarity to the flow of liquids through orifices, notches and weirs: Inst. Mech. Engineers, Proc., v. 1, p. 1033.

Numachi, F., Kurokawa, T., and Hutizawa, S., 1940, Über den Überfallbeiwert eines rechtwinkelig-dreieckigen Messwehrs: Soc. Mech. Engineeers (Japan) Trans., v. 6, no. 22, (February), p. 110. 
1941, Über den Überfallbeiwert eines rechtwinkelig-dreieckigen Messwehrs:

Tôhoku Imperial Univ., (Japan) Tech. reports, v. 13, no. 2, p. 350.

1943, Über den Überfallbeiwert eines rechtwinkelig-dreieckigen Messwehrs, 2.

Mitteilung: Tôhoku Imperial Univ., (Japan) Tech. reports, v. 13, no. 3, p. 473.

Rehbock, Th., 1929, discussion of paper by Ernest W. Schoder and Kenneth B. Turner,

Precise weir measurements: Am. Soc. Civil Engineers Trans., v. 93, p. 1148.

Schlag, Albert, 1962, Note sur la mesure des débits pour déversoir triangulare, La Tribune de Cebedeau (Liege, Belgium), v. 15, no. 218, p. 22.

$-1962 b$, Formule de débit de déversoirs dont le seuil est constitué par une série de dents situees dans un plan horizontal, La Tribune du Cebedeau (Liege, Belgium), v. 15 , no. 221 , p. 180 .

Smith, E. S., Jr., 1934, The V-notch weir for hot water: Am. Soc. Mech. Engineers Trans., v. 56, p. 787.

-1935, The V-notch weir for hot water: Am. Soc. Mech. Engineers Trans., v. 57, p. 249.

Strickland, T. P., 1910, Mr. James Barr's experiments upon the flow of water over triangular notches: Engineering (London), v. 90, (October 28), p. 598.

Switzer, F. G., 1915, Tests of the effect of temperature on weir coefficients: Engineering News, v. 73, no. 13, (April 1), p. 636.

Thomson, James, 1858, On experiments on the measurement of water by triangular notches in weir boards: Brit. Assoc. Adv. Sci., Annual report, p. 181.

1861, On experiments on the measurement of water by triangular notches in weir boards: Brit. Assoc. Adv. Sci., Annual report, p. 151.

Thornton, B. M., 1929, Measurement of fluid flow with triangular notches: Power Engineer (August), London, v. 24, p. 314.

Tracy, H. J., 1957, Discharge characteristics of broad-crested weirs: U.S. Geological Survey Circ. 397, 15 p., 11 figs.

Yarnall, D. R., 1912, the V-notch weir method of measurement: Am. Soc. Mech. Engineers Trans., v. 34, p. 1055.

1926, Accuracy of the V-notch weir method of measurement: Am. Soc. Mech. Engineers Trans., v. 48 , p. 939. 
SUPPLEMENTAL INFORMATION 


\section{REQUIREMENTS FOR PRECISE MEASUREMENTS}

\section{SPECIFICATIONS FOR THE INSTALLATION}

Use of the triangular-notch, thin-plate weir for precise measurements is restricted to steady, free, and fully ventilated flows. The recommended coefficients are applicable for water only, in the approximate range of temperatures from $40^{\circ} \mathrm{F}$ to $85^{\circ} \mathrm{F}$.

General specifications for a satisfactory weir installation are described on page B2. Additional restrictions related to the actual measurements are discussed below.

\section{RESTRICTIONS ON THE GEOMETRIC PARAMETERS}

Values of $\mathrm{v}$ less than $20^{\circ}$ or greater than $100^{\circ}$ are not recommended for precise measurements. Experimental data for weirs outside this range are limited. Furthermore, the data available indicate that weirs with very small and very large notch angles exhibit characteristics of instability which result from the fact that the nappe intermittently clings to the upper surfaces of the crest.

Practical restrictions on $h / P$ and $P / B$ are suggested by the observation that head-measurement difficulties and errors result from surges and waves which occur in the approach channel when the velocity of approach is large in comparison with the depth of flow. The available data are not adequate to establish the limiting values of $h / P$ and $P / B$ which are associated with this condition. Therefore, the user himself must determine practical limits which are consistent with the required accuracy for head measurements. These limits are separate from restrictions on the use of figure 12, which is applicable only when the effects of $h / P$ and $P / B$ are negligible.

\section{RESTRICTIONS ON $h$ AND $P$}

Restrictions on the magnitude of $h$ are related to the unpredictable, unsteady clinging phenomena which occur at small heads. To ensure a freely discharging, stable nappe, a minimum value of $h=0.2$ foot is recommended.

There is disagreement in the literature regarding an independent correlation between $P$ and the coefficient of discharge. It is tentatively recommended that $P$ be limited to values greater than 0.3 foot.

\section{EFFECT OF NEGLECTING $k_{h}$}

It is apparent from equations 5 and 6 that the relative influence of $k_{h}$ decreases as $h$ increases in magnitude. Consequently, the error which results from using $h$ instead of $h_{e}$ in equation 6 is appreciable only for small values of $h$. The relative error in the discharge is plotted as a function of $h$ in figure 20 . 


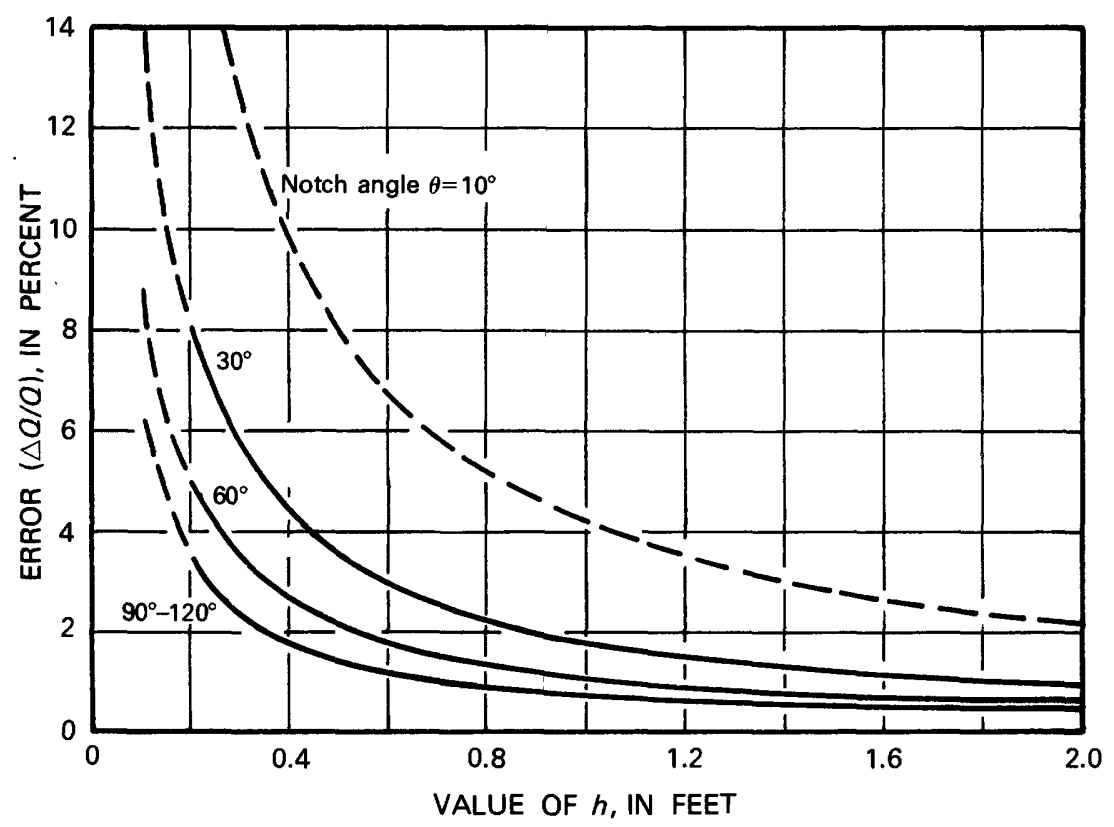

FIGURE 20. - Effect of using $h$ instead of $h_{e}$ in equation 6.

\section{EFFECT OF APPROACH-CHANNEL CONDITIONS}

Specifications for a satisfactory weir installation include the requirement that turbulence and velocity in the channel upstream from the weir be such as to simulate normal (uniform flow) conditions in a smooth, horizontal, rectangular channel. If the effective notch area is very small in comparison with the area of the approach channel, approach velocities are negligible, and the shape of the channel is insignificant. Short channels are satisfactory if they are provided with baffles capable of producing a nearly normal turbulence and velocity distribution. When in doubt, the velocity distribution should be checked with a velocity traverse located at or near the headwater-gage section.

The experimental data available are inadequate to evaluate the influence of velocity distribution over a full range of values of $\mathrm{v}, h / P$, and $P / B$. However, the remarkable consistency and agreement shown by the data plotted in figures 6 through 11 indicate a corresponding lack of correlation with the different approach-channel conditions which are represented by those data. Therefore, in the range of values of $h / P$ from 0.03 to 0.35 and $P / B$ from 0.1 to 1.5 , the influence of approach-channel velocity distribution is believed to be negligible. 


\section{MEASUREMENT OF v}

Precise discharge computations require that $\mathrm{v}$ be measured accurately. One of several satisfactory methods of measuring $v$ is described: (1) two true disks of different, micrometered diameters are placed in the rotch with their edges tangent to the sides of the notch; (2) the vertical distance between the centers (or two corresponding edges) of the two disks is measured with a micrometer caliper; (3) the angle $v$ is twice the angle whose sine is equal to the difference between the radii of the disks divided by the distance between the centers of the disks.

Other equally satisfactory methods of measuring $\mathrm{v}$ are described in the listed references.

\section{MEASUREMENT OF $h$}

The head is measured with a hook gage, point gage, or precise manometer. Hook and point gages preferably are used in a stilling well. However, if approach velocities and surface disturbances in the approach channel are negligible, the gages can be mounted over the headwater surfaces. Stilling wells and manometers are connected to piezometers located in the floor or walls of the channel. To prevent errors due to excessive head losses or surface drawdown, the piezometric section is located upstream from the weir a distance equal to from four to five times the maximum head. Gages are mounted as close to the weir as possible in order to avoid errors in the gage zero due to deflection or movement under different water loads.

\section{DETERMINATION OF GAGE ZERO}

Accuracy of head measurements is critically dependent upon the determination of the gage zero, which is defined as the gage reading corresponding to the level of the vertex of the notch. Numerous acceptable methods of determining the gage zero are in use. One such method is described: (1) still water in the channel upstream from the weir is drawn to a level below the vertex of the notch; (2) a temporary, precise hook gage is mounted over the approach channel, with its point a short distance upstream from the weir plate; (3) a true cylinder of known (micrometered) diameter is placed with its axis horizontal, with one end resting in the notch and the other end balanced on the point of the temporary hook gage; (4) a machinist's level is placed on the top of the cylinder and the hook gage is adjusted to make the cylinder precisely horizontal; (5) the reading of the temporary gage is recorded; and (6) the temporary hook gage is lowered to the water surface in the approach channel and the reading is recorded. 
The permanent headwater gage is adjusted to read the level in the stilling well, and this reading is recorded; (7) the distance from the bottom of the cylinder to the vertex of the notch is computed with the known values of $\mathrm{v}$ and the diameter of the cylinder; (8) the vertical distance from the vertex of the notch to the still surface is computed from the readings in step 5 and 6 and the computation in step 7; (9) finally, the zero reading on the permanent gage is computed as its reading on the still water surface plus the computed distance from the vertex to the still surface. An obvious advantage of this method is that it refers the gage zero to the geometrical vertex which is defined by the sides of the notch. 



\section{Studies of Flow of Water Over Weirs and Dams}

GEOLOGICAL SURVEY WATER-SUPPLY PAPER 1617

This volume was published as separate chapters $A-B$

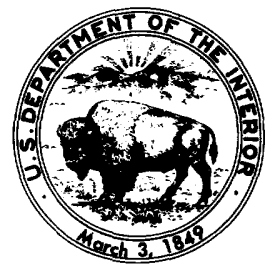


UNITED STATES DEPARTMENT OF THE INTERIOR

JAMES G. WATT, Secretary

GEOLOGICAL SURVEY

Doyle G. Frederick, Acting Director 


\section{CONTENTS}

[Letters designate the chapters]

(A) Studies of Flow of Water Over Weirs and Dams-Discharge Characteristics of Embankment-Shaped Weirs, by Carl E. Kindsvater.

(B) Studies of Flow of Water Over Weirs and Dams-Discharge Characteristics of Triangular-Notch Thin-Plate Weirs, by John Shen. 


